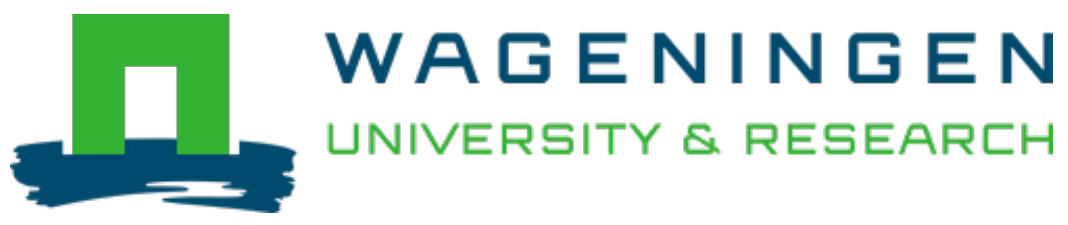

\author{
The effects of trapping effort and sources of variability on the estimation of \\ activity-density and diversity of carabids in annual field crops by pitfall trapping; \\ a meta-analysis \\ Entomologia Generalis \\ Saska, Pavel; Makowski, David; Bohan, David A.; Werf, Wopke \\ https://doi.org/10.1127/entomologia/2021/1211
}

This publication is made publicly available in the institutional repository of Wageningen University and Research, under the terms of article $25 \mathrm{fa}$ of the Dutch Copyright Act, also known as the Amendment Taverne. This has been done with explicit consent by the author.

Article $25 \mathrm{fa}$ states that the author of a short scientific work funded either wholly or partially by Dutch public funds is entitled to make that work publicly available for no consideration following a reasonable period of time after the work was first published, provided that clear reference is made to the source of the first publication of the work.

This publication is distributed under The Association of Universities in the Netherlands (VSNU) 'Article $25 \mathrm{fa}$ implementation' project. In this project research outputs of researchers employed by Dutch Universities that comply with the legal requirements of Article 25fa of the Dutch Copyright Act are distributed online and free of cost or other barriers in institutional repositories. Research outputs are distributed six months after their first online publication in the original published version and with proper attribution to the source of the original publication.

You are permitted to download and use the publication for personal purposes. All rights remain with the author(s) and / or copyright owner(s) of this work. Any use of the publication or parts of it other than authorised under article $25 \mathrm{fa}$ of the Dutch Copyright act is prohibited. Wageningen University \& Research and the author(s) of this publication shall not be held responsible or liable for any damages resulting from your (re)use of this publication.

For questions regarding the public availability of this publication please contact openscience.library@wur.nl 


\title{
The effects of trapping effort and sources of variability on the estimation of activity-density and diversity of carabids in annual field crops by pitfall trapping; a meta-analysis
}

\author{
Pavel Saska ${ }^{1, \star}$, David Makowskiं ${ }^{2}$, David A. Bohan ${ }^{3}$, and Wopke van der Werf ${ }^{4}$ \\ 1 Functional Diversity Group, Crop Research Institute, Drnovská 507, Prague 6, Ruzyně, 161 06, Czech Republic \\ 2 INRAE, UMR 518 AgroParisTech, INRAE, Université Paris-Saclay, 16 rue Claude Bernard, 75231 Paris Cedex 05, France \\ 3 Agroécologie, AgroSup Dijon, INRAE, Univ. Bourgogne, Univ. Bourgogne Franche-Comté, 21000 Dijon, France \\ ${ }^{4}$ Centre for Crop Systems Analysis, Wageningen University and Research, P.O. Box 430, 6700 AK Wageningen, \\ The Netherlands \\ * Corresponding author: saska@vurv.cz
}

With 6 figures and 1 table

\begin{abstract}
Pitfall trapping is widely used for studying the abundance and diversity of ground-dwelling arthropods and small vertebrates. Meta-analysis is a powerful technique to synthesize information across studies, but it requires standardization to make study results comparable. It has never been studied how results of pitfall trapping should be standardized to obtain estimates of activity-density and diversity that are comparable across studies. We analysed samples of Carabidae (Coleoptera) from annual crops, reported in 104 publications from Europe and North-America, spanning a period of 42 years, to find (i) a scaling for pitfall trapping effort to assess activity-density and diversity in pitfall catches across studies; and, (ii) to determine the sources of variability in the catch per unit effort. The total catch was proportional to the number of trap days, with a mean of 1.33 beetles/(trap days). The number of species was allometrically related to the trapping effort defined as the product of the number of traps, their perimeter and the time of exposure in the field. The mean species richness was 7.15 species/(m days) ${ }^{0.25}$. The size of the catch and the number of species adjusted per unit effort were higher in crops with narrow as compared to wide rows. Other factors were explored but were not influential. There was no significant change in abundance or diversity of carabids in arable land over the 42 years covered. The results give insight in factors affecting carabid abundance and diversity in field studies and enable standardization of pitfall catches across the literature.
\end{abstract}

Keywords: Carabidae; pitfall traps; sampling effort; trap days; catch per unit effort; decline in diversity; trappability

\section{Introduction}

Pitfall traps are commonly used to sample ground-dwelling invertebrates such as beetles or spiders (e.g. Luff 1975; Pekár 2002; Koivula et al. 2003; Hohbein \& Conway 2018), but also vertebrates such as terrestrial amphibians, reptiles and small mammals (e.g. Spence-Bailey et al. 2010; Bovendorp et al. 2017). The traps are typically plastic or glass containers sunk into the soil. Over 2,000 scientific papers have relied on this method since 2010 (2.028 publications, Science Citation Index Expanded, Web of Science, Clarivate Analytics, search string: "pitfall trap*" OR "pit-fall trap*", period 2010-2020, search performed on 7.9.2020). The focus of studies that used pitfall traps is diverse and includes studies in environmental monitoring, habitat conservation and restoration, pest and weed control and other ecosystem services, effects of agricultural management on biodiversity, animal movement and population studies, etc. Thus, there is an enormous body of literature potentially available for systematic evaluation e.g. through meta-analysis.

Evidence synthesis of the pitfall trap data across multiple independent studies is only meaningful if these are standardized for trapping effort, i.e., the number and sizes of traps, and the duration of the catching period. Finding a way to effectively standardize for the effect of trapping effort on the catch would make comparison of pitfall catches across studies possible, thus rendering useful the enormous corpus of published information that is currently inaccessible to systematic comparison. We are aware of no previous papers on the topic of standardizing pitfall trap catches for trapping effort across studies. 


\title{
The effects of trapping effort and sources of variability on the estimation of activity-density and diversity of carabids in annual field crops by pitfall trapping; a meta-analysis
}

\author{
Pavel Saska ${ }^{1, \star}$, David Makowskiं ${ }^{2}$, David A. Bohan ${ }^{3}$, and Wopke van der Werf ${ }^{4}$ \\ 1 Functional Diversity Group, Crop Research Institute, Drnovská 507, Prague 6, Ruzyně, 161 06, Czech Republic \\ 2 INRAE, UMR 518 AgroParisTech, INRAE, Université Paris-Saclay, 16 rue Claude Bernard, 75231 Paris Cedex 05, France \\ 3 Agroécologie, AgroSup Dijon, INRAE, Univ. Bourgogne, Univ. Bourgogne Franche-Comté, 21000 Dijon, France \\ ${ }^{4}$ Centre for Crop Systems Analysis, Wageningen University and Research, P.O. Box 430, 6700 AK Wageningen, \\ The Netherlands \\ * Corresponding author: saska@vurv.cz
}

With 6 figures and 1 table

\begin{abstract}
Pitfall trapping is widely used for studying the abundance and diversity of ground-dwelling arthropods and small vertebrates. Meta-analysis is a powerful technique to synthesize information across studies, but it requires standardization to make study results comparable. It has never been studied how results of pitfall trapping should be standardized to obtain estimates of activity-density and diversity that are comparable across studies. We analysed samples of Carabidae (Coleoptera) from annual crops, reported in 104 publications from Europe and North-America, spanning a period of 42 years, to find (i) a scaling for pitfall trapping effort to assess activity-density and diversity in pitfall catches across studies; and, (ii) to determine the sources of variability in the catch per unit effort. The total catch was proportional to the number of trap days, with a mean of 1.33 beetles/(trap days). The number of species was allometrically related to the trapping effort defined as the product of the number of traps, their perimeter and the time of exposure in the field. The mean species richness was 7.15 species/(m days) ${ }^{0.25}$. The size of the catch and the number of species adjusted per unit effort were higher in crops with narrow as compared to wide rows. Other factors were explored but were not influential. There was no significant change in abundance or diversity of carabids in arable land over the 42 years covered. The results give insight in factors affecting carabid abundance and diversity in field studies and enable standardization of pitfall catches across the literature.
\end{abstract}

Keywords: Carabidae; pitfall traps; sampling effort; trap days; catch per unit effort; decline in diversity; trappability

\section{Introduction}

Pitfall traps are commonly used to sample ground-dwelling invertebrates such as beetles or spiders (e.g. Luff 1975; Pekár 2002; Koivula et al. 2003; Hohbein \& Conway 2018), but also vertebrates such as terrestrial amphibians, reptiles and small mammals (e.g. Spence-Bailey et al. 2010; Bovendorp et al. 2017). The traps are typically plastic or glass containers sunk into the soil. Over 2,000 scientific papers have relied on this method since 2010 (2.028 publications, Science Citation Index Expanded, Web of Science, Clarivate Analytics, search string: "pitfall trap*" OR "pit-fall trap*", period 2010-2020, search performed on 7.9.2020). The focus of studies that used pitfall traps is diverse and includes studies in environmental monitoring, habitat conservation and restoration, pest and weed control and other ecosystem services, effects of agricultural management on biodiversity, animal movement and population studies, etc. Thus, there is an enormous body of literature potentially available for systematic evaluation e.g. through meta-analysis.

Evidence synthesis of the pitfall trap data across multiple independent studies is only meaningful if these are standardized for trapping effort, i.e., the number and sizes of traps, and the duration of the catching period. Finding a way to effectively standardize for the effect of trapping effort on the catch would make comparison of pitfall catches across studies possible, thus rendering useful the enormous corpus of published information that is currently inaccessible to systematic comparison. We are aware of no previous papers on the topic of standardizing pitfall trap catches for trapping effort across studies. 
There is a large body of work on rarefaction as a method to standardize results of studies or samples differing in sample size (Gotelli \& Colwell 2001). This method requires a full list of species and numbers caught, which is quite often not available in the published literature, and may be hard to obtain from the authors, especially for older studies. Therefore, rarefaction is difficult to use in a meta-analysis of factors affecting activity-density and diversity of carabids. While it seems evident that allowance should be made for the number of traps and the time of exposure, it has never been explored systematically whether expressing the catch per trap per time unit would result in comparable estimates across the literature, and whether the effect is not, in fact, non-linear, with the catch increasing less than proportional with the number of traps or less than proportional with the time of exposure when traps are exposed for a longer time in the field. Furthermore, Turin et al. (1991) have suggested that allowance should be made for the perimeter of traps. Likewise, traps can be equipped with funnels, they can contain liquid preservatives that could be attractive or repellent, etc. (e.g. Hohbein and Conway 2018). Finally, studies on carabid activity density and diversity are done in widely different experimental designs, including replicated field trials with small plots (and potentially with interplot interference) or in whole fields. All these factors related to experimental techniques and designs could affect the catch per unit effort. We are not aware of any studies that systematically explore possible sources of variability on catches of epigaeic arthropods in order to correct for those effects before comparing results of different studies when analysing the influence of ecological factors. Thus, the issue of standardization of catches across studies is unresolved and understudied. We therefore conduct a meta-analysis of published literature, considering annual field crops, and explore possible proxies for trapping effort that have a good relationship to the size and diversity of the catch.

Meta-analysis requires that the possible sources of variability are accounted for in order to reveal the overarching patterns of interest (Makowski et al. 2019). In the case of pitfall trap studies, sources of variability not only originate from experimental design and design of the traps, but also from presentation factors, i.e. the way the data are aggregated in the publications (e.g. as totals per field, averages over plots with the same treatment in a field experiment, fields falling in the same grouping in designed experiments with the field as experimental unit, or data aggregated over multiple years of trapping). The question remains to be addressed how to best generalise and integrate trapping effort in a meta-analysis while allowing for possible specific attributes of the source studies related to experimenting and presenting.

We chose carabid beetles as a model group of organisms because they are recognized as important biocontrol agents in agricultural crops, preying upon invertebrate pest species (Sunderland 2002) and eating and potentially regu- lating seeds of arable weeds (Bohan et al. 2011; Frei et al. 2019). Because of their important contribution to these ecological services, conservation and augmentation of stocks of carabids in farmland is an agro-ecological management aim (Brooks et al. 2012). Carabids also represent an excellent model for environmental monitoring and bio-indication because they respond to abiotic and biotic variation, and to disturbances and management (Kotze et al. 2011).

This paper addresses two aims. First, we aim to define a method for estimating the effect of trapping effort on the size and species diversity of the pitfall catch. An ideal standardization would assure that the catch is proportional to the trapping effort. Secondly, we explore here how factors related to experimenting and presentation affect the relationship between the catch and trapping effort. In our study, we focus on carabid samples from annual field crops.

\section{Materials and methods}

\subsection{Conceptualising the catch per unit effort of pitfall trapping}

As a null model, we assume an allometric relationship between the pitfall catch size, C, and trapping effort, $E$ :

$\log (C)=\beta_{0}+\beta_{1} \log (E) \Rightarrow C=e^{\beta_{0}} E^{\beta_{1}}$

where $C$ can represent the total number of individuals caught (total catch) and log is the natural logarithm. This null model also includes the possibility of a linear relationship between catch and trapping effort if $\beta_{1}=1$. Eq. 1 is related to the relationship frequently used in fisheries to evaluate the fish stock: $C=q E N$ (Harley et al. 2001; Martell 2008), in which $C$ is the catch, $N$ is the abundance of the individuals, $E$ is the fishing effort and $q$ is "catchability" related e.g. to animal behaviour and its spatial distribution. The catch per unit effort is then defined as: $C P U E=\frac{C}{E}$, and is assumed to be proportional to population size (Harley et al. 2001; Martell 2008). An equation analogous to eq. 1 can be constructed for the species richness in the catch, $S$ :

$\log (S)=\beta_{0}+\beta_{1} \log (E) \Rightarrow S=e^{\beta_{0}} E^{\beta_{1}}$

The constant $e^{\beta_{0}}$ in eq. 1 and 2 is the number of individuals or species caught per unit of effort $E$ raised to a power $\beta_{1}$, and represents in the case of eq. 1 the product of catchability (or better trappability if pitfall traps are considered) and abundance $(q N)$.

\subsection{Search strategy}

Searches were made in the Science Citation Index Expanded (SCI-E) and Scopus for the years 1945-2018 (Appendix S1). Search \#1 was made in SCI-E and covered the years of 
1991-2018, and used the following search string: (carabid* OR "ground beetle*") AND (field* OR crop*) AND (*icide* OR manag* OR control* OR organic* OR conventional* OR practice* OR cultivation OR till*) AND ("species richness" OR "number of species" OR diversity OR activity* OR abundan*) NOT (wood* OR forest* OR vineyard* OR olive* OR orchard* OR urban* OR wetland* OR highway*). Search \#2 was also made in SCI-E. It covered the years 1945-1990 and was less restrictive, because abstracts were not available for articles before 1991: (carabid* OR "ground beetle*") AND (*icide* OR manag* OR control* OR organic* OR conventional* OR practice* OR cultivation OR till*) NOT (wood* OR forest* OR vineyard* OR olive* OR orchard* OR urban* OR wetland* OR highway*). Search \#3 was made using Scopus (Elsevier) and covered the years 1960-2018: (carabid* OR "ground beetle*") AND (field* OR crop*) AND (*icide* OR manag* OR control* OR organic* OR conventional* OR practice* OR cultivation OR till*) AND ("species richness" OR "number of species" OR diversity OR activity* OR abundan*) AND NOT (wood* OR forest* OR vineyard* OR olive* OR orchard* OR urban* OR wetland* OR highway*). After removal of duplicates, this search resulted in 648 publications. Then, titles, keywords, abstracts and full text were screened retaining only those papers containing primary data on pitfall trapping of carabid beetles and including information on field and crop management. The final database comprised data from 104 publications (Appendix S2) and 810 data records.

\section{Data}

Information was aimed to be extracted from the source publications at the level of trapping season, experimental treatment, crop and experimental unit (i.e. plot or field), but in practice the resolution of data records was variable due to factors of presentation in the source studies. To account for these differences, we introduced the categorical variables Unit and Season (Table 1). Unit has three levels to make distinction between (1) experiments conducted in a single field with treatments (e.g. tillage) applied to plots, and the results being presented per treatment, (2) studies that were conducted in multiple fields, and where the publication reported data for each and every field separately, (3) studies that were conducted in multiple fields, but for which the data of individual fields were not identifiable because the data were presented per groups of fields with one or more common factor levels (e.g. organic vs conventional). Season has two levels to make distinction between studies that (1) reported data extractable for each trapping year separately and (2) pooled data over multiple years (Table 1). Altogether, we thus considered six levels of aggregation of the data collected in a single record when combining the information from these

Table 1. Data extracted from publications.

\begin{tabular}{|c|c|c|}
\hline Variable & Definition & Data type/Unit \\
\hline TotalCatch $(C)$ & Total number of individuals caught & Numerical \\
\hline SpeciesRichness $(S)$ & Total number of recorded species & Numerical \\
\hline Study & $\begin{array}{l}\text { Unique study identifier. Different countries sampled in the same publication were } \\
\text { considered as different studies }\end{array}$ & Categorical \\
\hline Continent & Continent where experiments were carried out & Categorical \\
\hline Country & Country where experiments were carried out & Categorical \\
\hline Unit & Aggregation over experimental unit (Plots/Single field/Multiple fields) & Categorical \\
\hline Season & Aggregation over trapping years (Single year/Multiple years) & Categorical \\
\hline Year & $\begin{array}{l}\text { Year when the sampling was conducted. If data from multiple years were aggregated, the } \\
\text { last one was recorded. }\end{array}$ & Numerical \\
\hline CropSpecies & Species of crop grown in the study season & Categorical \\
\hline RowWidth & $\begin{array}{l}\text { Interrow distance within the crop (Narrow: small grain cereals, oilseed rape and pea; } \\
\text { Wide: all the other crops) }\end{array}$ & Categorical \\
\hline TrapNumber $(K)$ & Number of traps used per record & Numerical \\
\hline TrapDiameter $(d)$ & Diameter of the pitfall trap used, if circular (m) & Numerical \\
\hline TrapSideLength $(l)$ & Length of trap side, if quadrate (m) & Numerical \\
\hline TrappingDays $(X)$ & Exposure time of traps (days) & Numerical \\
\hline Funnel & $\begin{array}{l}\text { Traps equipped with funnels or not. If not mentioned, it was assumed that funnels were } \\
\text { not used. }\end{array}$ & Categorical \\
\hline Fluid & Collecting fluid used. & Categorical \\
\hline
\end{tabular}


two variables (Unit - three levels; Season - two levels) (Appendix S3).

For each record, we calculated the total number of carabids caught over all pitfalls, and determined the total trapping effort (see below) (Table 1). Information on the number of carabid beetles caught was available from 101 publications. For these studies, we calculated $n=792$ values of the total number of carabids caught $(C)$. The total number of species $(S)$ was extracted from 49 publications with $n=335$ values. We consider several possible proxy variables to characterize trapping effort $E$ : number of traps $(K)$ (Kotze et al. 2012), total trap perimeter $(P)$ (Turin et al. 1991), duration of trap exposure (X) (Jung et al. 2019), trap-days ( $R$ ) (Kromp 1989), and a new metric - perimeter-days $(Q)$ (Table 1$)$. The total trap perimeter was calculated as $P=\pi d K$ for circular traps where $d$ is trap diameter (m) or as $P=4 l K$ for square traps where $l$ was the side length. The number of trap-days $(R)$ was calculated as $R=X K$, and perimeter-days $(Q)$ were calculated as $Q=X P$. Variables related to experimental technique, study design and trapping effort were extracted from each publication (Table 1).

\subsection{Statistical analysis}

In a first step of the analysis, we compared five different variables measuring trapping effort (see above) to standardize the total catch $(C)$ and species richness $(S)$. Based on a priori testing that included Gaussian, Poisson and negative binomial distributions, we used the Gaussian error structure and identity link (having both dependent and independent variables on the log scale) for total catch and the Poisson error structure with log-link for species richness (Appendix S4, Table S1). Analyses used mixed effects models in which random factors were included to account for effects of study and year of sampling within a study (models C1-25 and S1-25 in Appendix S4, Table S1). We selected as the best proxy for trapping effort the measure that was the most closely related to the total catch or species richness, as assessed by information criteria (AIC, BIC) and by the precision of the slope estimate of the model relating total catch or species richness to trapping effort. The best model was used to estimate the value of the slope parameter $\beta_{1}$ in order to test the key assumption that its value is 1 , i.e. proportionality between the catch or diversity and the effort without curvature (eqs. $1-2)$. Independent variables were centred to remove correlation between the slope and the intercept and to increase the robustness of fitting (models C26-27 and S26-27 in Appendix S4, Table S1). Since there was no measure of the variance available for the total catch or species richness in the source studies, we used as weights the measure of trapping effort, log-transformed to get the weighting variables to the same scale with the fixed effects variables (models C27 and S27 in Appendix S4, Table S1). The adequacy of including weights in the preferred models was assessed with AIC and BIC. All analyses were performed in R 3.6.1 (R Core Team 2019), and mixed effects models were fitted using lmer (total catch) or glmer (species richness) functions of the package lme4 (Bates et al. 2015).

In the second step of the analysis, we explored the effect of possible sources of variability on the catch per unit effort. We used as predictors the year of sampling (Year), continent (Continent), crops grouped in two categories according to row width (RowWidth), presence of a funnel (Funnel), type of collecting fluid (Fluid) and level of aggregation over experimental units (Unit) and over experimental seasons (Season) (Table 1). The effect of these variables was tested one by one by linear mixed effect models (function lmer) and generalized linear mixed effects model (function glmer). In order to take the effect of $E$ into account, we included $E^{\beta_{1}}$ as an offset (Kotze et al. 2012) in the models relating the observed values of $C$ and $S$ to the considered factors (models C28-35 and S28-35 in Appendix S4, Table S2). Because of missing data for RowWidth and Fluid in several records, we used a reduced data set in analyses including these variables ( $\mathrm{n}=721$ for individuals and $\mathrm{n}=305$ for species). The effect of the categorical variables (Unit, Season, Continent, RowWidth, Funnel, Fluid) was further assessed by comparing the cumulative distributions of the effort-adjusted catch and species richness, $\log \left(C P U E_{C}\right)=\log \left(\frac{C}{E^{\beta_{1}}}\right)$ and $\log \left(C P U E_{S}\right)=\log \left(\frac{S}{E^{\beta_{1}}}\right)$, respectively, for the groups of records using the Kolmogorov-Smirnov test.

As there was collinearity among predictor variables, we used multi-model inference (Burnham \& Anderson 2002; Grueber et al. 2011) to obtain an overall assessment of the importance of predictors. We formulated global models; one for the number of individuals caught and one for the observed species richness (models C36 and S36 in Table S3 in Appendix S4), and used the function dredge ( $\mathrm{R}$ package MuMIn; Barton 2009) to build simplified models by omitting variables from these global models, and then rank the resulting set of models according to information criteria. Random effects, weights and error structure were derived from the best models describing the relation between the catch with unit effort, including an offset related to sampling effort (defined as explained above). Fitted models were automatically ranked according to AICc and BIC, and the set of top models was delineated by 6 units of AICc or BIC, respectively (Grueber et al. 2011). Model averaging revealed the relative importance of explanatory variables based on the top models, along with the relationship between response and explanatory variables (Burnham \& Anderson 2002), and was performed using the function model.avg ( $R$ package MuMIn; Barton 2009). The parameters of the averaged model and their standard errors were estimated using the zero-method which calculates the weighted mean coefficient estimates over the selected models substituting a 
zero if a predictor was not selected in a model (Grueber et al. 2011). Marginal $\mathrm{R}^{2}$ values indicate the amount of variation explained by fixed factors only, while conditional $\mathrm{R}^{2}$ values represent the variance explained by both fixed and random factors (Nakagawa \& Schielzeth 2013); these metrics were calculated using the function r.squaredGLMM (R package MuMIn; Barton 2009).

\subsection{Publication bias}

Publication bias was assessed by constructing funnel plots for the $\log \left(C P U E_{C}\right)$ and $\log \left(C P U E_{S}\right)$. We used the $\log$ of the optimal expression of $E^{\beta_{1}}$ as the measure of study precision assuming that data records with exerted greater trapping effort will provide more precise estimate of the $C P U E_{C}$ and $C P U E_{S}$. There is no publication bias if the data points are symmetrically spread over the left and right side of the triangle. Points outside the funnel indicate possible outliers or heterogeneity in the data. Publication bias was assessed using all available data records.

\section{Results}

\subsection{Descriptive analysis}

Of the 104 studies, 68 originated from Europe and 36 from North America. Altogether the data came from 22 countries. Most publications came from the USA (28), Germany (21) and Canada (8).

Most records are based on sampling in a single season $(n=726)$; much fewer records were based on reporting over multiple seasons $(n=84)$ (Fig. 1a). There were slightly more records from Europe $(\mathrm{n}=451)$ than from North America $(n=359)$. Most of the data records came from experiments with treatments applied to replicate plots $(n=604)$, and fewer records were based on reporting catches in single fields $(\mathrm{n}=116)$ or over multiple fields $(\mathrm{n}=90)$. Plot-based studies were relatively more frequent in North America (ca. $87 \%$ of records) than in Europe (ca. 63 \%) (Fig. 1a).

The experimental crops were unevenly represented in the data set (Fig. 1c), with C4 cereals (mostly maize) and C3 cereals (mostly wheat or barley) dominating. Records for wide row crops were more frequent $(n=463)$ than for narrow row crops $(\mathrm{n}=300)$. Crops with wide row spacing are more common in North American than in European studies (Fig. 1a). In Europe, wide row crops were more frequent in plot-based studies than in studies conducted at the level of whole fields (Fig. 1b).

Studies which used funnels in the traps were less frequent $(n=140)$ than those without $(n=670)$. Funnels were more frequently used in North America (ca. $26 \%$ of records) than in Europe (10\% of records) (Fig. 1d). Altogether 16 different collecting fluids were used in this data set which were grouped in six categories (Fig. 1e). Traps to collect live beetles formed an additional category (Fig. 1e). The data set is dominated by fluids based on antifreeze compounds, followed by formaldehyde and water (usually containing salt) (Fig. 1e). Funnels were used only in traps that contained antifreeze compounds, alcohols and $\mathrm{CuSO}_{4}$ solution.

Data records originated from a period of sampling spanning 43 years, from 1973 to 2015 (Fig. 1f), but most records $(\mathrm{n}=499)$ came from studies conducted between the years 2000 and 2015.

Variability in continuous input variables related to trapping effort, total catch and observed species richness is shown in Appendix S5.

\subsection{Finding the optimal standardization of total catch and species richness per unit effort}

The total catch significantly increased with all measures of trapping effort. Trap-days, $R$, was superior to all other alternative measures of trapping effort (Appendix S6). Each of the criteria used for model comparison identified another model as best model. We chose a random intercept model (1|Study/Year; model C18 in Appendices S4 and S6) as our preferred model (Fig. 2a) because it estimated the slope parameter $\beta_{1}$ with greater accuracy than the random slope and intercept model $(1+\log (R) \mid$ Study/Year; model C20 in Appendices S4 and S6). The final model for standardizing the catch per unit effort (model C27 in Appendices S4 and S6) differed from the model $\mathrm{C} 18$ by centring the trap-days $R$ and using weights based on the trap-days ( $\triangle \mathrm{AIC}=16.8)$. The estimated slope value of this best model C27 was $\beta_{1}=$ $0.959 \pm 0.056$ which was not significantly different from 1 $(P=0.471)$, indicating that the number of individuals caught is proportional to the trapping effort expressed as trap-days, and the effort-adjusted catch is equivalent to $C P U E_{C}=\frac{C}{R}$. The mean $C P U E_{C}$ across the entire data set was $1.33 \pm 0.12$ individuals (trap days) $)^{-1}$, with $95 \%$ prediction interval of 0.19-9.53 beetles (trap days) ${ }^{-1}$.

Species richness increased significantly with all measures of trapping effort, and total perimeter-days $Q$ was the most effective measure of standardization (Appendix S6). A random intercept model was identified as best (1|Study/ Year; model S23 in Appendices S4 and S6), and was further improved by centring the perimeter-days $Q$ (model S26 in Appendices S4 and S6); adding weights according to the perimeter-days was not justified $(\triangle \mathrm{AIC}=573.8)$. The estimated value of the slope parameter in model S26 was $\beta_{1}=0.257 \pm 0.037$, indicating that the number of recorded species increases substantially less than proportionally with $Q$ (Fig. 2b-c). The effort-adjusted species richness is therefore equivalent to $C P U E_{S}=\frac{S}{Q^{0.25}}$. Mean $C P U E_{S}$ across the entire data set was $7.15 \pm 0.37$ species (m days) $)^{-0.25}$, with a $95 \%$ prediction interval of $2.30-13.18$ species (m days) $)^{-0.25}$. 


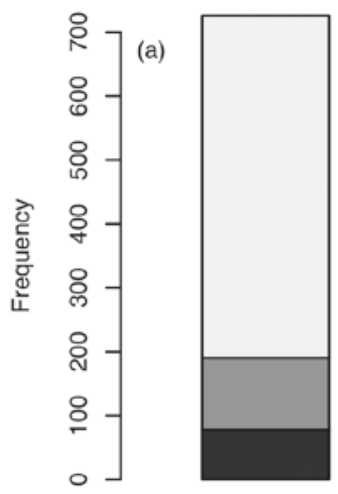

Single season $\square$ Plots

$\square$ Single fields

- Multiple fields

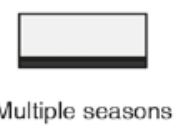

Multiple seasons
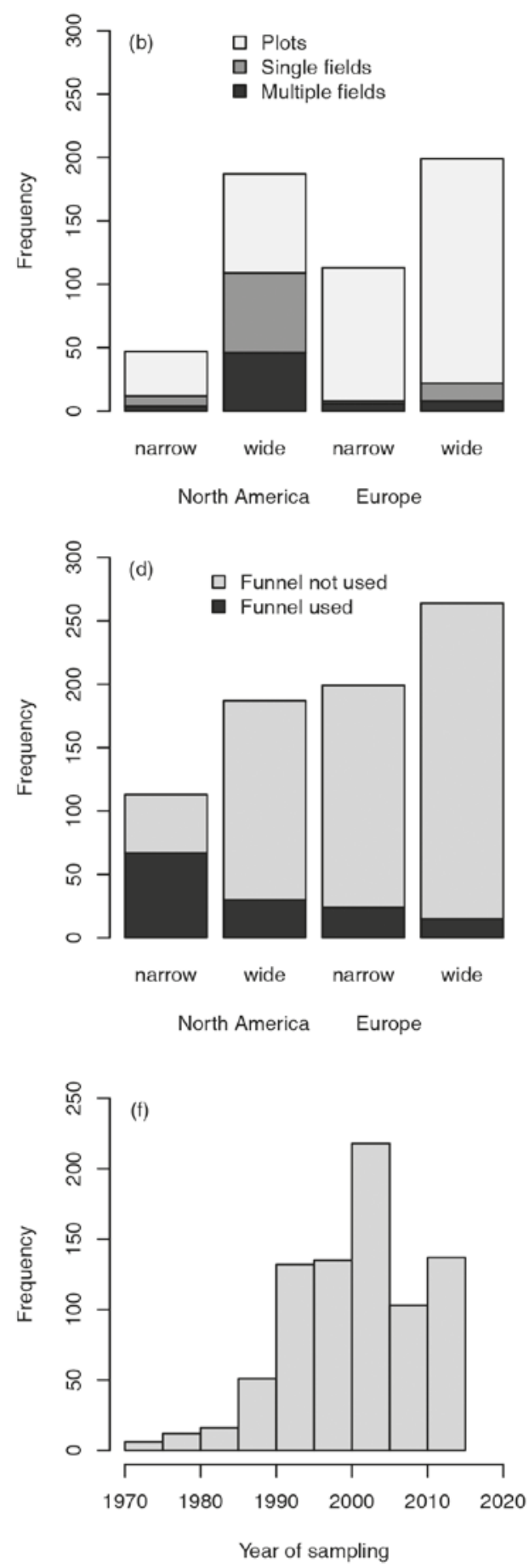

Fig. 1. Distribution of records in the data set with variables fundamental to the study design, sampling scheme and level of data aggregation in the source publications. (a) Number of data records according to aggregation over experimental units and sampling seasons. (b) Number of data records originating from North America and Europe, from crops with wide or narrow rows, and from plots, single fields, or multiple fields. (c) Number of data records related to experimental crops. C3 cereals include wheat $(n=141)$, barley (66), oats (3), triticale (2) and undefined cereals (10); C4 cereals include both sweet corn and corn for silage (260) and sorghum (2); legumes include pea (35), soybean (24), beans (18), lupin (6) and faba bean (4); root crops include potatoes (41), sugarbeet (31) and carrots (5); and vegetables consist of tomatoes (16), squash (10), melon (8), cauliflower (8), cabbage (7), zucchini (6) and onion (5). Cotton (6), oilseed rape (10) and sunflower (5) are single crop categories. (d) Number of data records based on trapping with or without funnels, and originating from North America or Europe, and from crops with wide or narrow rows. (e) Number of data records related to the collecting fluid used. Antifreeze include ethylene glycol (236), propylene glycol (171) and unspecified antifreeze (14), water includes water with (66) or without (41) diluted salt, alcohols include ethanol (17) and iso-propyl alcohol (8), other include $\mathrm{Na}_{3} \mathrm{PO}_{4}(4), \mathrm{CuSO}_{4}(12)$, natrium benzoate (2) and unspecified liquid (6), and acetic acid include mixtures that contain this ingredient (14). Formalin (144) and live traps without any collecting fluid (23) are single type categories; (f) Distribution of data records according to the year of sampling. 

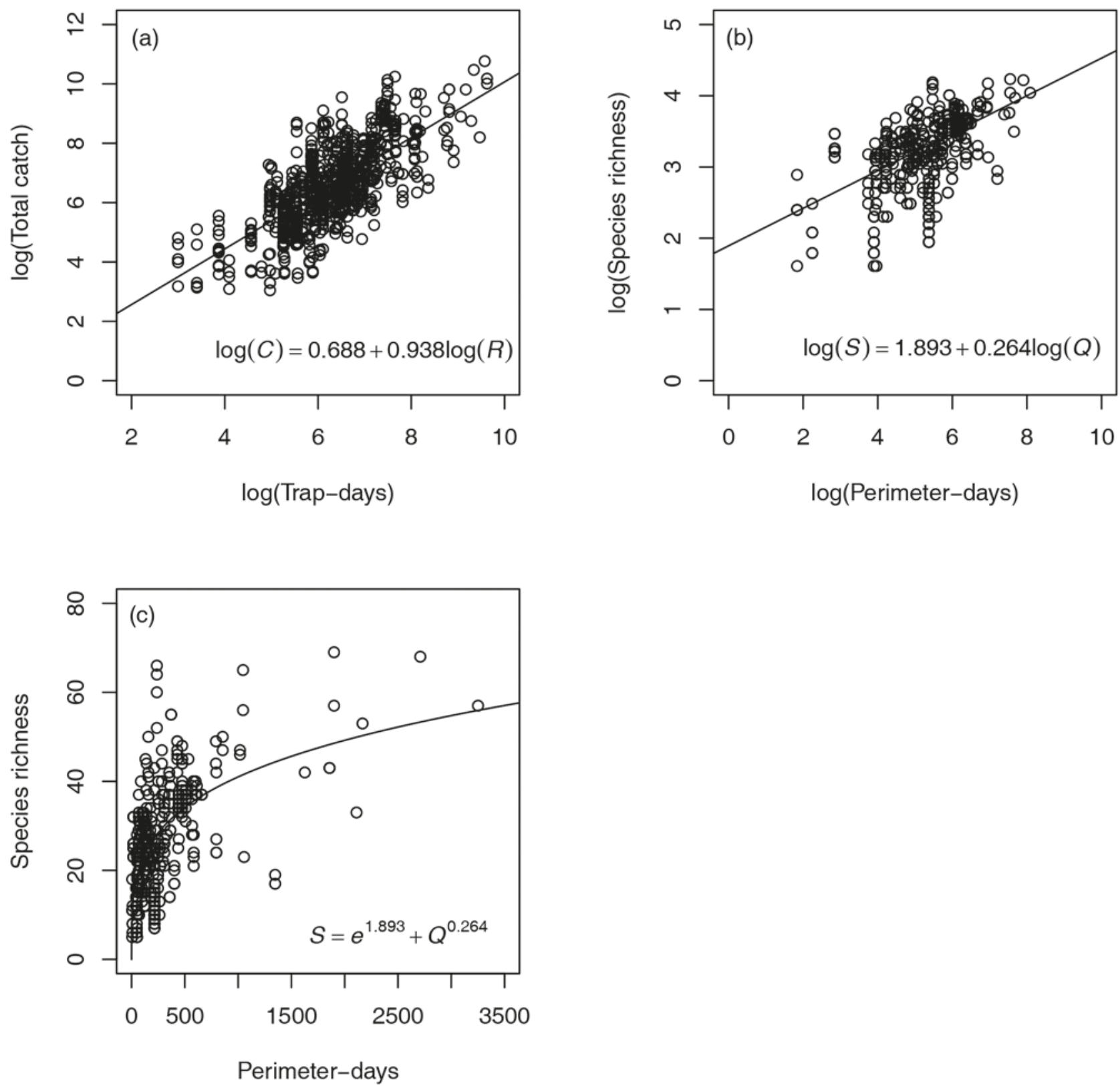

Fig. 2. Dependency of carabid pitfall catch on trapping effort. (a) The effect of trap-days (R) [log(trap days)] on the total catch [log(individuals)] (model C18 in Appendix S6); (b) The effect of perimeter-days (Q) [log(m days)] on the observed species richness $S$ [log(species)] (model S23 in Appendix S6); (c) same as (b) but on the natural scale.

\subsection{Factors influencing effort-adjusted catch size and species richness}

Models with single predictors indicated that effort-adjusted catch was significantly affected by Continent, Unit, RowWidth and Fluid, but not by Season and Funnel (Fig. 3). The $C P U E_{C}$ was on average $65 \%$ higher in Europe than in North America, and $32 \%$ lower in crops with wide rows than in crops with narrow rows. Records from multiple fields and plots had lower $C P U E_{C}$ by 39 and $53 \%$ than those from single fields. Live traps had $84 \%$ lower catch per unit effort, $C P U E_{C}$, than traps containing fluids based on acetic acid (which had the highest catch per unit effort), and 43 $\%$ less than traps with antifreeze-based fluids. The effortadjusted species richness was affected significantly by the RowWidth, Season and Funnel, but not by Continent, Unit and Fluid (Fig. 4). Effort-adjusted species richness, $C P U E_{S}$, was reduced by $29 \%$ in crops with wide rows compared to narrow rows, by $23 \%$ if data were aggregated over multiple seasons, but increased by $90 \%$ if funnels were used inside the traps. The analysis based on the comparison of the cumu- 
Continent

North America

Europe

Unit aggregation

multiple fields

single field

plots

Row width

narrow rows

wide rows

Season aggregation

single season

multiple seasons

Funnel

no funnel

funnel

Collecting fluid

acetic acid

alcohols

antifreeze

formalin

live

other

water

grand mean

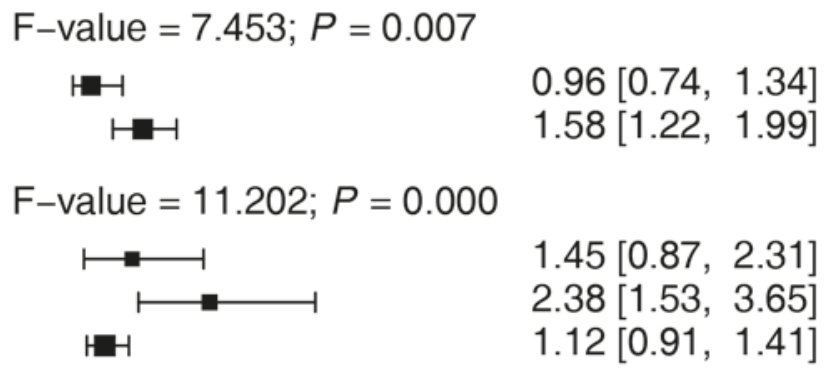

F-value $=16.827 ; P=0.000$

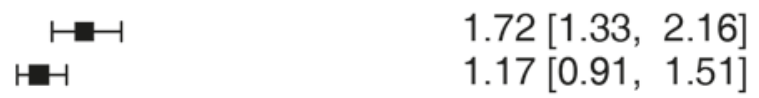

F-value $=0.205 ; P=0.651$

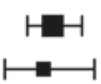

$1.35[1.05,1.70]$

$1.24[0.77,1.85]$

F-value $=0.004 ; P=0.947$

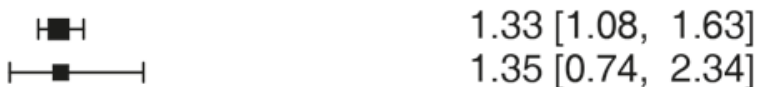

F-value $=3.109 ; P=0.008$

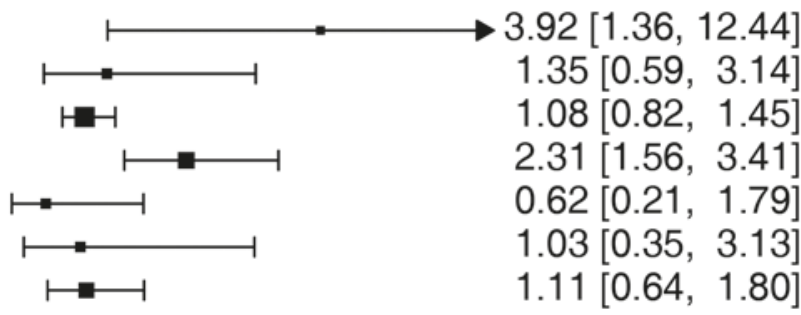

t-value $=3.164 ; P=0.002$

$1.33[1.08,1.61]$

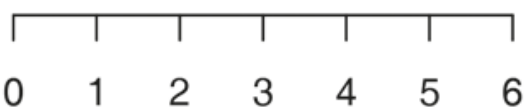

Estimated mean $C P U E_{C}$

Fig. 3. Estimated mean effort-adjusted catch, $C P U E_{C}$ [individuals (trap days)-1] , shown for variables potentially affecting the relationship with the pitfall catch and trapping effort. Size of the symbols are relative to sample size. Horizontal bars are $95 \% \mathrm{Cl}$ bootstrapped by the bootMer function (R package Ime4, 200 simulations).

lative probability distributions of $C P U E_{C}$ and $C P U E_{S}$ for the categorical variables provided results similar to the mixed models with single predictors (Appendix S7). Neither effortadjusted catch nor species richness showed a significant temporal trend over the period covered by this study (Fig. 5).

Multi-model inference lowered the level of significance of the factors influencing catch and number of species per unit effort. RowWidth was the only variable that significantly affected effort-adjusted catch in the averaged top models (Appendix S8), regardless of the information criterion used for model selection. The effect of other variables proposed by the single regression models (Fig. 3) cancelled each other out, probably due to correlations between inputs, but an important other explanation may be the reduced data set 


$\begin{array}{llr}\text { Continent } & \\ \text { North America } \\ \text { Europe }\end{array}$

Fig. 4. Estimated mean effort-adjusted species richness, $C P U E_{S}$ [species ( $m$ days)-0.25], shown for variables potentially affecting the relationship with the pitfall catch and trapping effort. Size of the symbols are relative to sample size. Horizontal bars are $95 \% \mathrm{Cl}$ bootstrapped by the bootMer function (R package Ime4, 200 simulations).

used for multi-model inference as only data records without missing data were included in this analysis. Using AICc, $C P U E_{C}$ was $30 \%$ lower in crops with wide rows than in crops with narrow rows (z-value $=3.788, P<0.001$ ), which is consistent with results of the single variable models. The values estimated based on BIC weights were similar to those calculated with AICc weights.
Effort-adjusted species richness was significantly affected by RowWidth, Funnel and Season if the model selection was based on AICc, and only by RowWidth if the model selection was based on BIC. Crops with wide rows reduced the $C P U E_{S}$ by $22 \%$ (AICc; z-value $=3.564, P<0.001$; BICbased selection gave very similar values), the use of a funnel increase the $C P U E_{S}$ by $66 \%$ (AICc; z-value $=2.603$, 

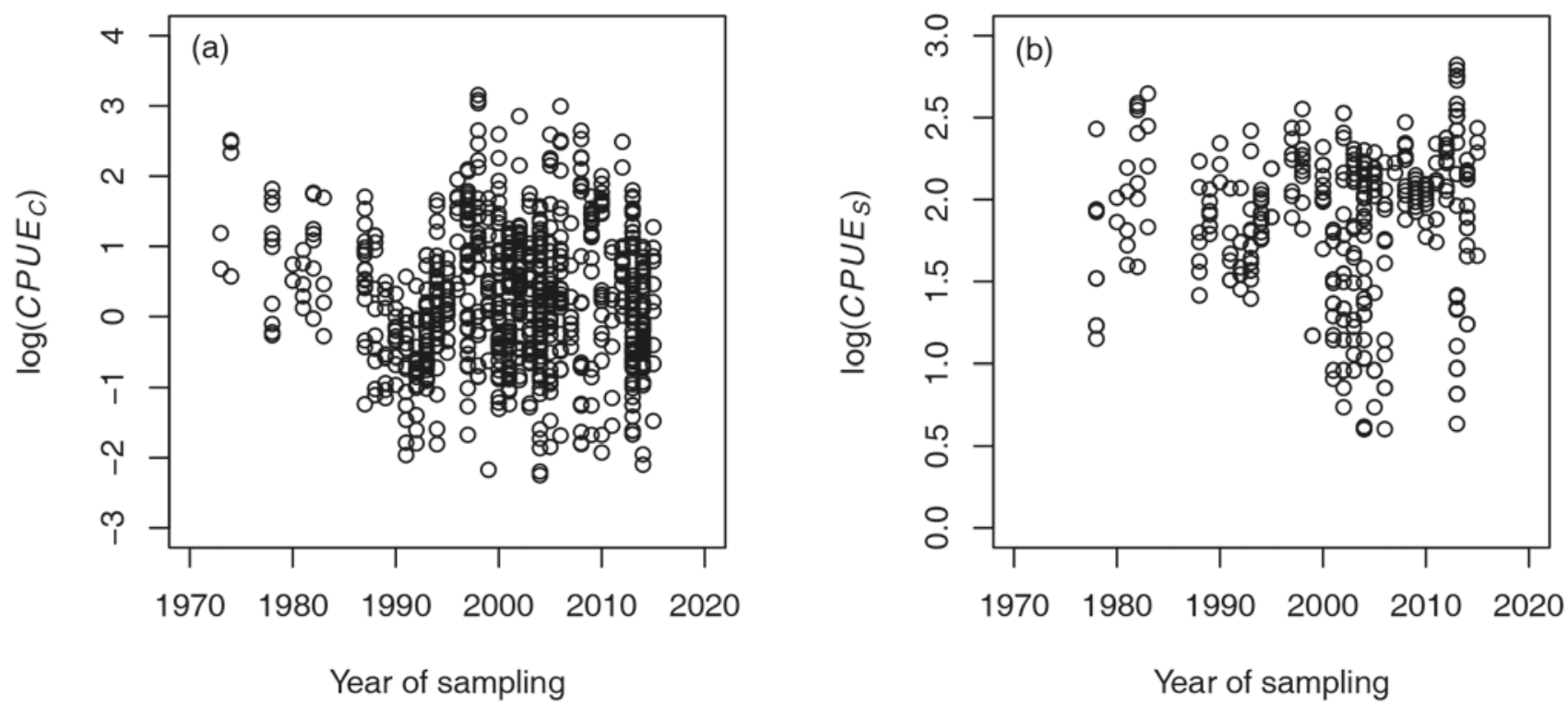

Fig. 5. Variation in the effort-adjusted catch, $C P U E_{C}$ [individuals (trap days)-1] (a), and effort-adjusted species richness, $C P U E_{S}$ [species ( $m$ days $)^{-0.25}$ (b) over the years of sampling covered by the data set.
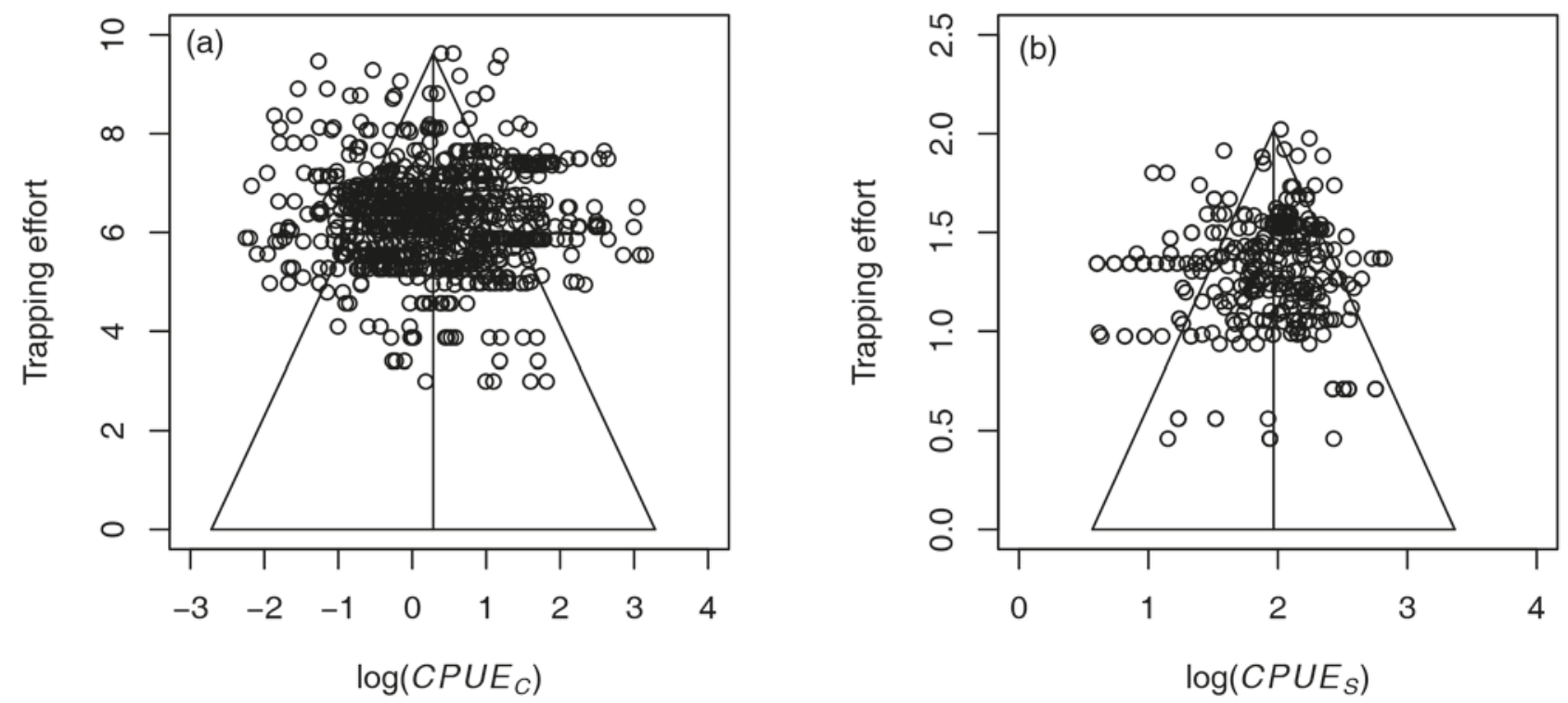

Fig. 6. Assessment of publication bias in the data included in the meta-analysis, using funnel plots of the effort-adjusted catch [log(individuals (trap days) $\left.{ }^{-1}\right)$ ] against trapping effort as trap-days [log(trap days)] (a), and the effort-adjusted species richness $\left[\log \left(\right.\right.$ species $\left.\left.(m \text { days })^{-0.25}\right)\right]$ against trapping effort as perimeter-days $\left[\log \left((m \text { days })^{0.25}\right)\right](\mathbf{b})$. The vertical lines represent the overall means on the log scale, as predicted by the null models. Log is the natural logarithm.

$P=0.009)$, and aggregation of data over multiple seasons reduced the $C P U E_{S}$ by $26 \%$ (AICc; $\mathrm{z}$-value $=2.075, P=$ 0.038). These values are also close to the results of single variable regression models (see above).

\subsection{Publication bias}

Studies with trapping effort of less than 20 trap days $(R=$ $\left.e^{3}\right)$, or ca. $1.7 \mathrm{~m} \mathrm{~d}\left(Q=e^{0.5}\right)$ were absent from the literature (Fig. 6). The variability in the $\log \left(C P U E_{C}\right)$ or $\log \left(C P U E_{S}\right)$ did not change with trapping effort (Fig. 6), which suggests 
that the variability is unrelated to the study precision and represents biological variation.

\section{Discussion}

This analysis showed that trap days was the most suitable measure for expressing trapping effort when analysing the number of carabid beetles caught in pitfall traps. The exponent of the allometric relationship was not significantly different from 1 , indicating that the catch is proportional to trapping effort, without significant curvature or saturation in the relationship. The best measure to express trapping effort when analysing species diversity of the catch was the number of meter days to the power of 0.25 , where the meters refer to total perimeter length of all traps while days refers to the time of trap exposure in the field. The exponent value of ca. 0.25 was significantly less than 1 , indicating that the relationship between trapping effort and species diversity is strongly non-linear, with species diversity increasing quite slowly with increases in effort, as measured by the number of traps, their perimeter, and the time of exposure. The finding of proportionality between the catch and effort in terms of trap-days validates the frequently-made presumption that the efficiency of trapping does not diminish with greater density of traps or longer time in the field. This conclusion is of course limited to the range of trap numbers and trapping durations commonly considered in this field of research and it is not implied that trapping efficiency could not be affected, e.g. when excessive numbers of traps are used. Also, the result is consistent over carabid communities that greatly differed in their composition.

We also found large heterogeneity across the records, demonstrating the importance of the local conditions for determination of the actual effort-corrected catch and richness, and this is largely captured by the random terms of the models. Large heterogeneity across the records would also suggest that to obtain more information about arthropod communities in arable land, it is of greater importance to sample more locations and more different conditions, than to expend additional trapping effort in any particular location or condition. The number of traps and fields in a sample should be determined by the question and the effect size researchers wish to detect, using power analyses (e.g. Perry et al. 2003; Bolker, 2008).

Although the single variable regression models identified multiple variables that were related to the effort-adjusted catch and species richness, model averaging indicated that the contrast between wide and narrow row crops was the major factor while other variables did not have an identifiable contribution to the catch or diversity in an overarching multi-variable analysis. This discrepancy between the two approaches may be due to the fact that the influence of particular factors, though locally important, were confounded and thus cancel each other out in a global analysis. Lower power of the model averaging may also contribute to less significant results as this analysis was based only on ca. 90 $\%$ of the records. Single variable analyses can use all the data that have the results for the studied independent variable whereas the model averaging requires information on all the independent variables. Based on both analyses, we conclude that no concern is needed in a future (meta-) analysis about the variability in experimental design, presentation, trap design or other factors varying across source studies when conducting meta-analyses on carabid activity-density and diversity. Nevertheless, standardization of the pitfall catch for effort is still needed to make comparison across studies possible.

Crops with wide or narrow rows differ in structure and phenology. Crops with wider rows (e.g. corn) constitute a less favourable environment, because there is greater proportion of bare soil that needs longer time to reach a closed canopy. Bare soil is unfavourable for many carabid species since exposure increases the risk of predation (Eyre et al. 2013; Seidl et al. 2020), and diurnal changes in microclimate are more prominent in wide row crops than under a more closed crop canopy (Rosenberg et al. 1983; Krédl et al. 2013). Crops with wider rows also allow crop management, such as mechanical weed control, which may be more intensive and extend longer over the season, potentially disturbing development stages of carabids present in soil.

The effort-adjusted species richness was affected by the level of data aggregation over trapping years (i.e. single year vs. multiple years) and the use of funnels inside the traps. The former can readily be explained by the fact that even though the local populations of carabids species show asynchronous fluctuations between seasons (Kotze et al. 2011), which results in a change in the relative contribution of particular species to the catch between years (e.g. Veselý \& Sarapatka 2008), the number of newly recorded species per year on sites sampled for multiple seasons is low. Increasing the trapping effort over more seasons on the same site brings disproportionately fewer new species recorded than adding a new site, sampled with the same effort. The presence of funnels increased observed species richness, which may be associated with a reduction in the probability of escaping from the traps (Obrist \& Duelli 1996). Interestingly, the use of funnels did not affect the number of individuals caught.

We were unable to detect trends in $C P U E_{C}$ or $C P U E_{S}$ over the 43 years covered by the data set, suggesting that carabid populations have not declined in abundance or diversity in arable fields on a broader geographical scale over this period. This result was remarkable and in contrast to the monitoring programmes on local (Pozsgai et al. 2016; van Noordwijk et al. 2017) or national scales (Brooks et al. 2012; Ewald et al. 2015), which have found carabid populations to have declined over time, as well as with general perception that insect populations decline in terrestrial ecosystems (Eggleton 2020; van Klink et al. 2020). Since the present data set originates from many local independent 
studies performed in different years, it may be less sensitive to site-specific inter-annual fluctuations (Kotze et al. 2011). A biological explanation for the lack of any trend might be that species inhabiting annual arable fields are adapted to early successional stages of vegetation development that arable fields are in fact representing, and to periodical disturbances due to management measures within the fields. Given that local declines of carabids, as well as other insects, have been observed in non-crop semi-natural habitats (Brooks et al. 2012; Poszgai et al. 2016; Hallmann et al. 2017) a reasonable expectation would be that this decline should spill over into arable fields as many carabid species recolonize fields from these non-crop habitats (Tscharntke et al. 2005). The present data, however, do not provide support for this assumption. Evaluating whether the community composition of the study group had changed in arable fields over the years was not, however, possible for our data because this evaluation would require different data extraction procedures than we have employed.

Pitfall catches cannot be directly interpreted as abundance estimates because the number of trapped individuals depends not only on their population density but also on their activity (particularly movement speed) and behaviour (Heydemann 1957; Adis 1979; Mols 1993; Wallin \& Ekbom 1994; Saska et al. 2013; Engel et al. 2017). Our results do beg the question: "Can the newly established relationships for CPUE help us to relate the size of the pitfall catch to the real densities or diversity of carabid population in the field?" Not on its own, but since we resolved one of variables from the relationship between the catch size and density, $C=q E N$, (Harley et al. 2001; Martell 2008), i.e. trapping effort $(E)$, we have advanced closer to a reliable approximation of the field densities and diversity from the pitfall trap catches. What remains to be investigated is the quantification of trappability coefficients $q$ for a range of species, because the likelihood of being trapped is likely to be species specific and size dependent (Halsall \& Wratten 1988; Engel et al. 2017). Thus, eq. 1 can be further extended to consider species specific trappability coefficient $q_{i}$. A relationship for $C P U E_{C}$, with species-specific catches $C_{i}$ and trapping effort expressed as trap-days $R$ would be:

$\log \left(\frac{\sum C_{i}}{R}\right)=\log \left(\sum q_{i} N_{i}\right)$

Trappability coefficients $q_{i}$ can be obtained by trapping beetles in enclosures with natural or manipulated densities, in various environments and in different abiotic conditions.

In this paper we establish relationships for the catch of carabid beetles, expressed as the number of individuals and the number of species, as a function of the pitfall trapping effort.

This method could be very useful for revealing the effects on carabid communities of other variables of inter- est related to agricultural management, such as pesticide and herbicide use, tillage, fertilization, crop seasonality and crop rotations that potentially affect carabid diversity and ecosystem functions. These will be investigated in a follow-up study.

This method applied here to carabid beetles could similarly be applied to other taxa with similar ecology, trapped using pitfalls, including ectothermic vertebrates or small mammals, or for other trapping devices that give activitydensity estimates, such as window or suction traps used for collecting flying insects. Standardization of the pitfall catch for trapping effort will be very useful in future systematic comparisons of multiple independent catches, since the data collected in various conditions are thus made more comparable. This approach removes one of the obstacles that has hampered meta-analyses of pitfall trap data.

Authors' contribution: PS, WvdW and DB conceived the study; PS, DM and WvdW conceptualized the analysis; PS performed the literature search, extracted the data, performed the analysis, created tables and figures, and led writing of the manuscript; DM, DB and WvdW contributed to writing and edited the final version; all authors have read and approved the final version of this paper.

Data availability: Data is available with the first author upon reasonable request.

Acknowledgements: This work was conducted within an ERANET C-IPM project BioAWARE. The stay of P.S. at Wageningen University was funded by the Mobility EU-Funds project CZ.02.2. 69/0.0/0.0/16_027/0008503, awarded to the Crop Research Institute. Finishing of the work was supported by the institutional support from the Ministry of Agriculture of the Czech Republic - MZE-RO0418.

\section{References}

Adis, J. (1979). Problems of interpreting arthropod sampling with pitfall traps. Zoologischer Anzeiger, 202, 177-184.

Barton, K. (2009). MuMIn: Multi-model inference. R package. http://R-Forge.R-project.org/projects/mumin/

Bates, D., Machler, M., Bolker, B. M., \& Walker, S. C. (2015). Fitting Linear Mixed-Effects Models Using lme4. Journal of Statistical Software, 67(1), 1-48. https://doi.org/10.18637/jss. v067.i01

Bohan, D. A., Boursault, A., Brooks, D. R., \& Petit, S. (2011). National-scale regulation of the weed seedbank by carabid predators. Journal of Applied Ecology, 48(4), 888-898. https://doi. org/10.1111/j.1365-2664.2011.02008.x

Bolker, B. M. (2008). Ecological Models and Data in R. Princeton University Press.

Bovendorp, R. S., Mccleery, R. A., \& Galetti, M. (2017). Optimising sampling methods for small mammal communities in Neotropical rainforests. Mammal Review, 47(2), 148-158. https://doi.org/10.1111/mam.12088 
Brooks, D. R., Bater, J. E., Clark, S. J., Monteith, D. T., Andrews, C., Corbett, S. J., ... Chapman, J. W. (2012). Large carabid beetle declines in a United Kingdom monitoring network increases evidence for a widespread loss in insect biodiversity. Journal of Applied Ecology, 49(5), 1009-1019. https://doi.org/10.1111/ j.1365-2664.2012.02194.x

Burnham, K. P., \& Anderson, D. R. (2002). Model Selection and Multimodel Inference: A Practical Information-Theoretic Approach. New York: Springer-Verlag.

Eggleton, P. (2020). The State of the World's Insects. Annual Review of Environment and Resources, 45(1), 61-82. https:// doi.org/10.1146/annurev-environ-012420-050035

Engel, J., Hertzog, L., Tiede, J., Wagg, C., Ebeling, A., Briesen, H., \& Weisser, W. W. (2017). Pitfall trap sampling bias depends on body mass, temperature, and trap number: Insights from an individual-based model. Ecosphere, 8(4), e01790. https://doi.org/ $10.1002 /$ ecs 2.1790

Ewald, J. A., Wheatley, C. J., Aebischer, N. J., Moreby, S. J., Duffield, S. J., Crick, H. Q. P., \& Morecroft, M. B. (2015). Influences of extreme weather, climate and pesticide use on invertebrates in cereal fields over 42 years. Global Change Biology, 21(11), 3931-3950. https://doi.org/10.1111/gcb.13026

Eyre, M. D., Luff, M. L., \& Leifert, C. (2013). Crop, field boundary, productivity and disturbance influences on ground beetles (Coleoptera, Carabidae) in the agroecosystem. Agriculture, Ecosystems \& Environment, 165, 60-67. https://doi.org/ 10.1016/j.agee.2012.12.009

Frei, B., Guenay, Y., Bohan, D. A., Traugott, M., \& Wallinger, C. (2019). Molecular analysis indicates high levels of carabid weed seed consumption in cereal fields across Central Europe. Journal of Pest Science, 92(3), 935-942. https://doi.org/10.1007/s10340019-01109-5

Gotelli, N. J., \& Colwell, R. K. (2001). Quantifying biodiversity: procedures and pitfalls in the measurement and comparison of species richness. Ecology Letters 4, 379-391.

Grueber, C. E., Nakagawa, S., Laws, R. J., \& Jamieson, I. G. (2011). Multimodel inference in ecology and evolution: Challenges and solutions. Journal of Evolutionary Biology, 24(4), 699-711. https://doi.org/10.1111/j.1420-9101.2010.02210.x

Hallmann, C. A., Sorg, M., Jongejans, E., Siepel, H., Hofland, N., Schwan, H., ... de Kroon, H. (2017). More than 75 percent decline over 27 years in total flying insect biomass in protected areas. PLoS One, 12(10), e0185809. https://doi.org/10.1371/ journal.pone.0185809

Halsall, N. B., \& Wratten, S. D. (1988). The efficiency of pitfall trapping for polyphagous predatory Carabidae. Ecological Entomology, 13(3), 293-299. https://doi.org/10.1111/j.13652311.1988.tb00359.x

Harley, S. J., Myers, R. A., \& Dunn, A. (2001). Is catch-per-uniteffort proportional to abundance? Canadian Journal of Fisheries and Aquatic Sciences, 58(9), 1760-1772. https://doi.org/ 10.1139/f01-112

Heydemann, B. (1957). Die Biotopstructur als Raumwiderstand und Raumfülle für die Tierwelt. Verhandlungen der Deutschen Zoologischen Gesellschaft Hamburg, 332-347.

Hohbein, R. R., \& Conway, C. J. (2018). Pitfall traps: A review of methods for estimating arthropod abundance. Wildlife Society Bulletin, 42(4), 597-606. https://doi.org/10.1002/wsb.928

Jung, J.-K., Jeong, J.-C., \& Lee, J.-H. (2019). Effects of pitfall trap size and sampling duration on collection of ground beetles
(Coleoptera: Carabidae) in temperate forests. Entomological Research, 49(5), 229-236. https://doi.org/10.1111/1748-5967. 12358

Koivula, M., Kotze, D. J., Hiisivuori, L., \& Rita, H. (2003). Pitfall trap efficiency: Do trap size, collecting fluid and vegetation structure matter? Entomologica Fennica, 14(1), 1-14. https:// doi.org/10.33338/ef.84167

Kotze, D. J., Brandmayr, P., Casale, A., Dauffy-Richard, E., Dekoninck, W., Koivula, M. J., ... Zetto, T. (2011). Forty years of carabid beetle research in Europe - from taxonomy, biology, ecology and population studies to bioindication, habitat assessment and conservation. ZooKeys, 100, 55-148. https://doi. org/10.3897/zookeys.100.1523

Kotze, D. J., O’Hara, R. B., \& Lehvävirta, S. (2012). Dealing with varying detection probability, unequal sample sizes and clumped distributions in count data. PLoS One, 7(7), e40923. https://doi. org/10.1371/journal.pone.0040923

Krédl, Z., Středa, T., Pokorny, R., Kmoch, M., \& Brotan, J. (2013). Microclimate in the vertical profile of wheat, rape and maize canopies. Acta Universitatis Agriculturae et Silviculturae Mendelianae Brunensis, 60(1), 79-90. https://doi.org/10.11118/ actaun201260010079

Kromp, B. (1989). Carabid beetle communities (Carabidae, Coleoptera) in biologically and conventionally farmed agroecosystems. Agriculture, Ecosystems \& Environment, 27(1-4), 241-251. https://doi.org/10.1016/0167-8809(89)90089-3

Luff, M. L. (1975). Some features influencing the efficiency of pitfall traps. Oecologia, 19(4), 345-357. https://doi.org/10.1007/ BF00348110

Makowski, D., Piraux, F., \& Brun, F. (2019). From Experimental Network to Meta-analysis. Mehods and Applications with $R$ for Agronomic ad Environmental Sciences. Dordrecht: Springer.

Martell, S. J. D. (2008). Fisheries Management. In S. E. Jørgensen \& B. D. Fath (Eds.), Encyclopedia of Ecology (pp. 1572-1582). Oxford: Academic Press. https://doi.org/10.1016/B978-0080 45405-4.00206-8

Mols, P. J. M. (1993). Walking to survive. Searching, feeding and egg production of the carabid beetles Pterostichus coerulescens L. (= Poecilus versicolor Sturm). Ph.D. Thesis, Agricultural University Wageningen.

Nakagawa, S., \& Schielzeth, H. (2013). A general and simple method for obtaining R2 from generalized linear mixed-effects models. Methods in Ecology and Evolution, 4(2), 133-142. https://doi.org/10.1111/j.2041-210x.2012.00261.x

Obrist, M., \& Duelli, P. (1996). Trapping efficiency of funnel and cup-traps for epigeal arthropods. Mitteilungen der Schweizerische Entomologische Gesellschaft, 69, 361-369.

Pekár, S. (2002). Differential effects of formaldehyde concentration and detergent on the catching efficiency of surface active arthropods by pitfall traps. Pedobiologia, 46(6), 539-547. https://doi. org/10.1078/0031-4056-00158

Perry, J. N., Rothery, P., Clark, S. J., Heard, M. S., \& Hawes, C. (2003). Design, analysis and statistical power of the Farm-Scale Evaluations of genetically modified herbicide-tolerant crops. Journal of Applied Ecology, 40(1), 17-31. https://doi.org/ 10.1046/j.1365-2664.2003.00786.x

Pozsgai, G., Baird, J., Littlewood, N. A., Pakeman, R. J., \& Young, M. R. (2016). Long-term changes in ground beetle (Coleoptera: Carabidae) assemblages in Scotland. Ecological Entomology, 41(2), 157-167. https://doi.org/10.1111/een.12288 
R Core Team (2019). R: A Language and Environment for Statistical Computing. R Foundation for Statistical Computing, Vienna, Austria. Available at http://www.R-project.org

Rosenberg, N. J., Blad, B. L., \& Verma, S. B. (1983). Microclimate: The Biological Environment. Wiley.

Saska, P., van der Werf, W., Hemerik, L., Luff, M. L., Hatten, T. D., \& Honek, A. (2013). Temperature effects on pitfall catches of epigeal arthropods: A model and method for bias correction. Journal of Applied Ecology, 50(1), 181-189. https://doi. org/10.1111/1365-2664.12023

Seidl, M., Gonzalez, E., Kadlec, T., Saska, P., \& Knapp, M. (2020). Temporary non-crop habitats within arable fields: The effects of field defects on carabid beetle assemblages. Agriculture, Ecosystems \& Environment, 293, 106856. https://doi.org/ 10.1016/j.agee.2020.106856

Spence-Bailey, L. M., Nimmo, D. G., Kelly, L. T., Bennett, A. F., \& Clarke, M. F. (2010). Maximising trapping efficiency in reptile surveys: The role of seasonality, weather conditions and moon phase on capture success. Wildlife Research, 37(2), 104-115. https://doi.org/10.1071/WR09157

Sunderland, K. D. (2002). Invertebrate pest control by carabids. In J. M. Holland (Ed.), The Agroecology of Carabid Beetles (pp. 165-214). Andover: Intercept.

Tscharntke, T., Rand, T. A., \& Bianchi, F. J. J. A. (2005). The landscape context of trophic interactions: Insect spillover across the crop-noncrop interface. Annales Zoologici Fennici, 42, 421-432.

Turin, H., Alders, K., den Boer, P. J., van Essen, S., Heijerman, T., Laane, W., \& Penterman, E. (1991). Ecological characterization of carabid species (Coleoptera, Carabidae) in the Netherlands from thirty years of pitfall sampling. Tijdschrift voor Entomologie, 134, 279-304. van Klink, R., Bowler, D. E., Gongalsky, K. B., Swengel, A. B., Gentile, A., \& Chase, J. M. (2020). Meta-analysis reveals declines in terrestrial but increases in freshwater insect abundances. Science, 368(6489), 417-420. https://doi.org/10.1126/ science.aax 9931

van Noordwijk, C. G. E., Baeten, L., Turin, H., Heijerman, T., Alders, K., Boer, P., ... Bonte, D. (2017). 17 years of grassland management leads to parallel local and regional biodiversity shifts among a wide range of taxonomic groups. Biodiversity and Conservation, 26(3), 717-734. https://doi.org/10.1007/ s10531-016-1269-5

Veselý, M., \& Sarapatka, B. (2008). Effects of conversion to organic farming on carabid beetles (Carabidae) in experimental fields in the Czech Republic. Biological Agriculture and Horticulture, 25(4), 289-309. https://doi.org/10.1080/01448765.2008.9755057

Wallin, H., \& Ekbom, B. (1994). Influence of hunger level and prey densities on movement patterns in three species of Pterostichus beetles (Coleoptera: Carabidae). Environmental Entomology, 23(5), 1171-1181. https://doi.org/10.1093/ee/23.5.1171

\section{The pdf version (Adobe JavaScript must be enabled) of this paper includes an electronic supplement: Supplement S1-S8}

Manuscript received: 6 October 2020

Revisions requested: 9 November 2020

Modified version received: 16 November 2020

Accepted: 15 December 2020 
There is a large body of work on rarefaction as a method to standardize results of studies or samples differing in sample size (Gotelli \& Colwell 2001). This method requires a full list of species and numbers caught, which is quite often not available in the published literature, and may be hard to obtain from the authors, especially for older studies. Therefore, rarefaction is difficult to use in a meta-analysis of factors affecting activity-density and diversity of carabids. While it seems evident that allowance should be made for the number of traps and the time of exposure, it has never been explored systematically whether expressing the catch per trap per time unit would result in comparable estimates across the literature, and whether the effect is not, in fact, non-linear, with the catch increasing less than proportional with the number of traps or less than proportional with the time of exposure when traps are exposed for a longer time in the field. Furthermore, Turin et al. (1991) have suggested that allowance should be made for the perimeter of traps. Likewise, traps can be equipped with funnels, they can contain liquid preservatives that could be attractive or repellent, etc. (e.g. Hohbein and Conway 2018). Finally, studies on carabid activity density and diversity are done in widely different experimental designs, including replicated field trials with small plots (and potentially with interplot interference) or in whole fields. All these factors related to experimental techniques and designs could affect the catch per unit effort. We are not aware of any studies that systematically explore possible sources of variability on catches of epigaeic arthropods in order to correct for those effects before comparing results of different studies when analysing the influence of ecological factors. Thus, the issue of standardization of catches across studies is unresolved and understudied. We therefore conduct a meta-analysis of published literature, considering annual field crops, and explore possible proxies for trapping effort that have a good relationship to the size and diversity of the catch.

Meta-analysis requires that the possible sources of variability are accounted for in order to reveal the overarching patterns of interest (Makowski et al. 2019). In the case of pitfall trap studies, sources of variability not only originate from experimental design and design of the traps, but also from presentation factors, i.e. the way the data are aggregated in the publications (e.g. as totals per field, averages over plots with the same treatment in a field experiment, fields falling in the same grouping in designed experiments with the field as experimental unit, or data aggregated over multiple years of trapping). The question remains to be addressed how to best generalise and integrate trapping effort in a meta-analysis while allowing for possible specific attributes of the source studies related to experimenting and presenting.

We chose carabid beetles as a model group of organisms because they are recognized as important biocontrol agents in agricultural crops, preying upon invertebrate pest species (Sunderland 2002) and eating and potentially regu- lating seeds of arable weeds (Bohan et al. 2011; Frei et al. 2019). Because of their important contribution to these ecological services, conservation and augmentation of stocks of carabids in farmland is an agro-ecological management aim (Brooks et al. 2012). Carabids also represent an excellent model for environmental monitoring and bio-indication because they respond to abiotic and biotic variation, and to disturbances and management (Kotze et al. 2011).

This paper addresses two aims. First, we aim to define a method for estimating the effect of trapping effort on the size and species diversity of the pitfall catch. An ideal standardization would assure that the catch is proportional to the trapping effort. Secondly, we explore here how factors related to experimenting and presentation affect the relationship between the catch and trapping effort. In our study, we focus on carabid samples from annual field crops.

\section{Materials and methods}

\subsection{Conceptualising the catch per unit effort of pitfall trapping}

As a null model, we assume an allometric relationship between the pitfall catch size, C, and trapping effort, $E$ :

$\log (C)=\beta_{0}+\beta_{1} \log (E) \Rightarrow C=e^{\beta_{0}} E^{\beta_{1}}$

where $C$ can represent the total number of individuals caught (total catch) and log is the natural logarithm. This null model also includes the possibility of a linear relationship between catch and trapping effort if $\beta_{1}=1$. Eq. 1 is related to the relationship frequently used in fisheries to evaluate the fish stock: $C=q E N$ (Harley et al. 2001; Martell 2008), in which $C$ is the catch, $N$ is the abundance of the individuals, $E$ is the fishing effort and $q$ is "catchability" related e.g. to animal behaviour and its spatial distribution. The catch per unit effort is then defined as: $C P U E=\frac{C}{E}$, and is assumed to be proportional to population size (Harley et al. 2001; Martell 2008). An equation analogous to eq. 1 can be constructed for the species richness in the catch, $S$ :

$\log (S)=\beta_{0}+\beta_{1} \log (E) \Rightarrow S=e^{\beta_{0}} E^{\beta_{1}}$

The constant $e^{\beta_{0}}$ in eq. 1 and 2 is the number of individuals or species caught per unit of effort $E$ raised to a power $\beta_{1}$, and represents in the case of eq. 1 the product of catchability (or better trappability if pitfall traps are considered) and abundance $(q N)$.

\subsection{Search strategy}

Searches were made in the Science Citation Index Expanded (SCI-E) and Scopus for the years 1945-2018 (Appendix S1). Search \#1 was made in SCI-E and covered the years of 
1991-2018, and used the following search string: (carabid* OR "ground beetle*") AND (field* OR crop*) AND (*icide* OR manag* OR control* OR organic* OR conventional* OR practice* OR cultivation OR till*) AND ("species richness" OR "number of species" OR diversity OR activity* OR abundan*) NOT (wood* OR forest* OR vineyard* OR olive* OR orchard* OR urban* OR wetland* OR highway*). Search \#2 was also made in SCI-E. It covered the years 1945-1990 and was less restrictive, because abstracts were not available for articles before 1991: (carabid* OR "ground beetle*") AND (*icide* OR manag* OR control* OR organic* OR conventional* OR practice* OR cultivation OR till*) NOT (wood* OR forest* OR vineyard* OR olive* OR orchard* OR urban* OR wetland* OR highway*). Search \#3 was made using Scopus (Elsevier) and covered the years 1960-2018: (carabid* OR "ground beetle*") AND (field* OR crop*) AND (*icide* OR manag* OR control* OR organic* OR conventional* OR practice* OR cultivation OR till*) AND ("species richness" OR "number of species" OR diversity OR activity* OR abundan*) AND NOT (wood* OR forest* OR vineyard* OR olive* OR orchard* OR urban* OR wetland* OR highway*). After removal of duplicates, this search resulted in 648 publications. Then, titles, keywords, abstracts and full text were screened retaining only those papers containing primary data on pitfall trapping of carabid beetles and including information on field and crop management. The final database comprised data from 104 publications (Appendix S2) and 810 data records.

\section{Data}

Information was aimed to be extracted from the source publications at the level of trapping season, experimental treatment, crop and experimental unit (i.e. plot or field), but in practice the resolution of data records was variable due to factors of presentation in the source studies. To account for these differences, we introduced the categorical variables Unit and Season (Table 1). Unit has three levels to make distinction between (1) experiments conducted in a single field with treatments (e.g. tillage) applied to plots, and the results being presented per treatment, (2) studies that were conducted in multiple fields, and where the publication reported data for each and every field separately, (3) studies that were conducted in multiple fields, but for which the data of individual fields were not identifiable because the data were presented per groups of fields with one or more common factor levels (e.g. organic vs conventional). Season has two levels to make distinction between studies that (1) reported data extractable for each trapping year separately and (2) pooled data over multiple years (Table 1). Altogether, we thus considered six levels of aggregation of the data collected in a single record when combining the information from these

Table 1. Data extracted from publications.

\begin{tabular}{|c|c|c|}
\hline Variable & Definition & Data type/Unit \\
\hline TotalCatch $(C)$ & Total number of individuals caught & Numerical \\
\hline SpeciesRichness $(S)$ & Total number of recorded species & Numerical \\
\hline Study & $\begin{array}{l}\text { Unique study identifier. Different countries sampled in the same publication were } \\
\text { considered as different studies }\end{array}$ & Categorical \\
\hline Continent & Continent where experiments were carried out & Categorical \\
\hline Country & Country where experiments were carried out & Categorical \\
\hline Unit & Aggregation over experimental unit (Plots/Single field/Multiple fields) & Categorical \\
\hline Season & Aggregation over trapping years (Single year/Multiple years) & Categorical \\
\hline Year & $\begin{array}{l}\text { Year when the sampling was conducted. If data from multiple years were aggregated, the } \\
\text { last one was recorded. }\end{array}$ & Numerical \\
\hline CropSpecies & Species of crop grown in the study season & Categorical \\
\hline RowWidth & $\begin{array}{l}\text { Interrow distance within the crop (Narrow: small grain cereals, oilseed rape and pea; } \\
\text { Wide: all the other crops) }\end{array}$ & Categorical \\
\hline TrapNumber $(K)$ & Number of traps used per record & Numerical \\
\hline TrapDiameter $(d)$ & Diameter of the pitfall trap used, if circular (m) & Numerical \\
\hline TrapSideLength $(l)$ & Length of trap side, if quadrate (m) & Numerical \\
\hline TrappingDays $(X)$ & Exposure time of traps (days) & Numerical \\
\hline Funnel & $\begin{array}{l}\text { Traps equipped with funnels or not. If not mentioned, it was assumed that funnels were } \\
\text { not used. }\end{array}$ & Categorical \\
\hline Fluid & Collecting fluid used. & Categorical \\
\hline
\end{tabular}


two variables (Unit - three levels; Season - two levels) (Appendix S3).

For each record, we calculated the total number of carabids caught over all pitfalls, and determined the total trapping effort (see below) (Table 1). Information on the number of carabid beetles caught was available from 101 publications. For these studies, we calculated $n=792$ values of the total number of carabids caught $(C)$. The total number of species $(S)$ was extracted from 49 publications with $n=335$ values. We consider several possible proxy variables to characterize trapping effort $E$ : number of traps $(K)$ (Kotze et al. 2012), total trap perimeter $(P)$ (Turin et al. 1991), duration of trap exposure (X) (Jung et al. 2019), trap-days ( $R$ ) (Kromp 1989), and a new metric - perimeter-days $(Q)$ (Table 1$)$. The total trap perimeter was calculated as $P=\pi d K$ for circular traps where $d$ is trap diameter (m) or as $P=4 l K$ for square traps where $l$ was the side length. The number of trap-days $(R)$ was calculated as $R=X K$, and perimeter-days $(Q)$ were calculated as $Q=X P$. Variables related to experimental technique, study design and trapping effort were extracted from each publication (Table 1).

\subsection{Statistical analysis}

In a first step of the analysis, we compared five different variables measuring trapping effort (see above) to standardize the total catch $(C)$ and species richness $(S)$. Based on a priori testing that included Gaussian, Poisson and negative binomial distributions, we used the Gaussian error structure and identity link (having both dependent and independent variables on the log scale) for total catch and the Poisson error structure with log-link for species richness (Appendix S4, Table S1). Analyses used mixed effects models in which random factors were included to account for effects of study and year of sampling within a study (models C1-25 and S1-25 in Appendix S4, Table S1). We selected as the best proxy for trapping effort the measure that was the most closely related to the total catch or species richness, as assessed by information criteria (AIC, BIC) and by the precision of the slope estimate of the model relating total catch or species richness to trapping effort. The best model was used to estimate the value of the slope parameter $\beta_{1}$ in order to test the key assumption that its value is 1 , i.e. proportionality between the catch or diversity and the effort without curvature (eqs. $1-2)$. Independent variables were centred to remove correlation between the slope and the intercept and to increase the robustness of fitting (models C26-27 and S26-27 in Appendix S4, Table S1). Since there was no measure of the variance available for the total catch or species richness in the source studies, we used as weights the measure of trapping effort, log-transformed to get the weighting variables to the same scale with the fixed effects variables (models C27 and S27 in Appendix S4, Table S1). The adequacy of including weights in the preferred models was assessed with AIC and BIC. All analyses were performed in R 3.6.1 (R Core Team 2019), and mixed effects models were fitted using lmer (total catch) or glmer (species richness) functions of the package lme4 (Bates et al. 2015).

In the second step of the analysis, we explored the effect of possible sources of variability on the catch per unit effort. We used as predictors the year of sampling (Year), continent (Continent), crops grouped in two categories according to row width (RowWidth), presence of a funnel (Funnel), type of collecting fluid (Fluid) and level of aggregation over experimental units (Unit) and over experimental seasons (Season) (Table 1). The effect of these variables was tested one by one by linear mixed effect models (function lmer) and generalized linear mixed effects model (function glmer). In order to take the effect of $E$ into account, we included $E^{\beta_{1}}$ as an offset (Kotze et al. 2012) in the models relating the observed values of $C$ and $S$ to the considered factors (models C28-35 and S28-35 in Appendix S4, Table S2). Because of missing data for RowWidth and Fluid in several records, we used a reduced data set in analyses including these variables ( $\mathrm{n}=721$ for individuals and $\mathrm{n}=305$ for species). The effect of the categorical variables (Unit, Season, Continent, RowWidth, Funnel, Fluid) was further assessed by comparing the cumulative distributions of the effort-adjusted catch and species richness, $\log \left(C P U E_{C}\right)=\log \left(\frac{C}{E^{\beta_{1}}}\right)$ and $\log \left(C P U E_{S}\right)=\log \left(\frac{S}{E^{\beta_{1}}}\right)$, respectively, for the groups of records using the Kolmogorov-Smirnov test.

As there was collinearity among predictor variables, we used multi-model inference (Burnham \& Anderson 2002; Grueber et al. 2011) to obtain an overall assessment of the importance of predictors. We formulated global models; one for the number of individuals caught and one for the observed species richness (models C36 and S36 in Table S3 in Appendix S4), and used the function dredge ( $\mathrm{R}$ package MuMIn; Barton 2009) to build simplified models by omitting variables from these global models, and then rank the resulting set of models according to information criteria. Random effects, weights and error structure were derived from the best models describing the relation between the catch with unit effort, including an offset related to sampling effort (defined as explained above). Fitted models were automatically ranked according to AICc and BIC, and the set of top models was delineated by 6 units of AICc or BIC, respectively (Grueber et al. 2011). Model averaging revealed the relative importance of explanatory variables based on the top models, along with the relationship between response and explanatory variables (Burnham \& Anderson 2002), and was performed using the function model.avg ( $R$ package MuMIn; Barton 2009). The parameters of the averaged model and their standard errors were estimated using the zero-method which calculates the weighted mean coefficient estimates over the selected models substituting a 
zero if a predictor was not selected in a model (Grueber et al. 2011). Marginal $\mathrm{R}^{2}$ values indicate the amount of variation explained by fixed factors only, while conditional $\mathrm{R}^{2}$ values represent the variance explained by both fixed and random factors (Nakagawa \& Schielzeth 2013); these metrics were calculated using the function r.squaredGLMM (R package MuMIn; Barton 2009).

\subsection{Publication bias}

Publication bias was assessed by constructing funnel plots for the $\log \left(C P U E_{C}\right)$ and $\log \left(C P U E_{S}\right)$. We used the $\log$ of the optimal expression of $E^{\beta_{1}}$ as the measure of study precision assuming that data records with exerted greater trapping effort will provide more precise estimate of the $C P U E_{C}$ and $C P U E_{S}$. There is no publication bias if the data points are symmetrically spread over the left and right side of the triangle. Points outside the funnel indicate possible outliers or heterogeneity in the data. Publication bias was assessed using all available data records.

\section{Results}

\subsection{Descriptive analysis}

Of the 104 studies, 68 originated from Europe and 36 from North America. Altogether the data came from 22 countries. Most publications came from the USA (28), Germany (21) and Canada (8).

Most records are based on sampling in a single season $(n=726)$; much fewer records were based on reporting over multiple seasons $(n=84)$ (Fig. 1a). There were slightly more records from Europe $(\mathrm{n}=451)$ than from North America $(n=359)$. Most of the data records came from experiments with treatments applied to replicate plots $(n=604)$, and fewer records were based on reporting catches in single fields $(\mathrm{n}=116)$ or over multiple fields $(\mathrm{n}=90)$. Plot-based studies were relatively more frequent in North America (ca. $87 \%$ of records) than in Europe (ca. 63 \%) (Fig. 1a).

The experimental crops were unevenly represented in the data set (Fig. 1c), with C4 cereals (mostly maize) and C3 cereals (mostly wheat or barley) dominating. Records for wide row crops were more frequent $(n=463)$ than for narrow row crops $(\mathrm{n}=300)$. Crops with wide row spacing are more common in North American than in European studies (Fig. 1a). In Europe, wide row crops were more frequent in plot-based studies than in studies conducted at the level of whole fields (Fig. 1b).

Studies which used funnels in the traps were less frequent $(n=140)$ than those without $(n=670)$. Funnels were more frequently used in North America (ca. $26 \%$ of records) than in Europe (10\% of records) (Fig. 1d). Altogether 16 different collecting fluids were used in this data set which were grouped in six categories (Fig. 1e). Traps to collect live beetles formed an additional category (Fig. 1e). The data set is dominated by fluids based on antifreeze compounds, followed by formaldehyde and water (usually containing salt) (Fig. 1e). Funnels were used only in traps that contained antifreeze compounds, alcohols and $\mathrm{CuSO}_{4}$ solution.

Data records originated from a period of sampling spanning 43 years, from 1973 to 2015 (Fig. 1f), but most records $(\mathrm{n}=499)$ came from studies conducted between the years 2000 and 2015.

Variability in continuous input variables related to trapping effort, total catch and observed species richness is shown in Appendix S5.

\subsection{Finding the optimal standardization of total catch and species richness per unit effort}

The total catch significantly increased with all measures of trapping effort. Trap-days, $R$, was superior to all other alternative measures of trapping effort (Appendix S6). Each of the criteria used for model comparison identified another model as best model. We chose a random intercept model (1|Study/Year; model C18 in Appendices S4 and S6) as our preferred model (Fig. 2a) because it estimated the slope parameter $\beta_{1}$ with greater accuracy than the random slope and intercept model $(1+\log (R) \mid$ Study/Year; model C20 in Appendices S4 and S6). The final model for standardizing the catch per unit effort (model C27 in Appendices S4 and S6) differed from the model $\mathrm{C} 18$ by centring the trap-days $R$ and using weights based on the trap-days ( $\triangle \mathrm{AIC}=16.8)$. The estimated slope value of this best model C27 was $\beta_{1}=$ $0.959 \pm 0.056$ which was not significantly different from 1 $(P=0.471)$, indicating that the number of individuals caught is proportional to the trapping effort expressed as trap-days, and the effort-adjusted catch is equivalent to $C P U E_{C}=\frac{C}{R}$. The mean $C P U E_{C}$ across the entire data set was $1.33 \pm 0.12$ individuals (trap days) $)^{-1}$, with $95 \%$ prediction interval of 0.19-9.53 beetles (trap days) ${ }^{-1}$.

Species richness increased significantly with all measures of trapping effort, and total perimeter-days $Q$ was the most effective measure of standardization (Appendix S6). A random intercept model was identified as best (1|Study/ Year; model S23 in Appendices S4 and S6), and was further improved by centring the perimeter-days $Q$ (model S26 in Appendices S4 and S6); adding weights according to the perimeter-days was not justified $(\triangle \mathrm{AIC}=573.8)$. The estimated value of the slope parameter in model S26 was $\beta_{1}=0.257 \pm 0.037$, indicating that the number of recorded species increases substantially less than proportionally with $Q$ (Fig. 2b-c). The effort-adjusted species richness is therefore equivalent to $C P U E_{S}=\frac{S}{Q^{0.25}}$. Mean $C P U E_{S}$ across the entire data set was $7.15 \pm 0.37$ species (m days) $)^{-0.25}$, with a $95 \%$ prediction interval of $2.30-13.18$ species (m days) $)^{-0.25}$. 


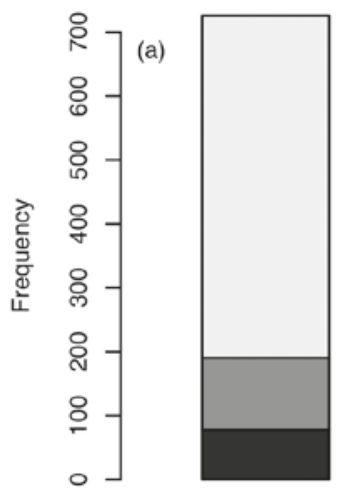

Single season $\square$ Plots

$\square$ Single fields

- Multiple fields

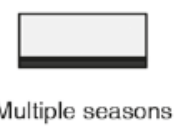

Multiple seasons
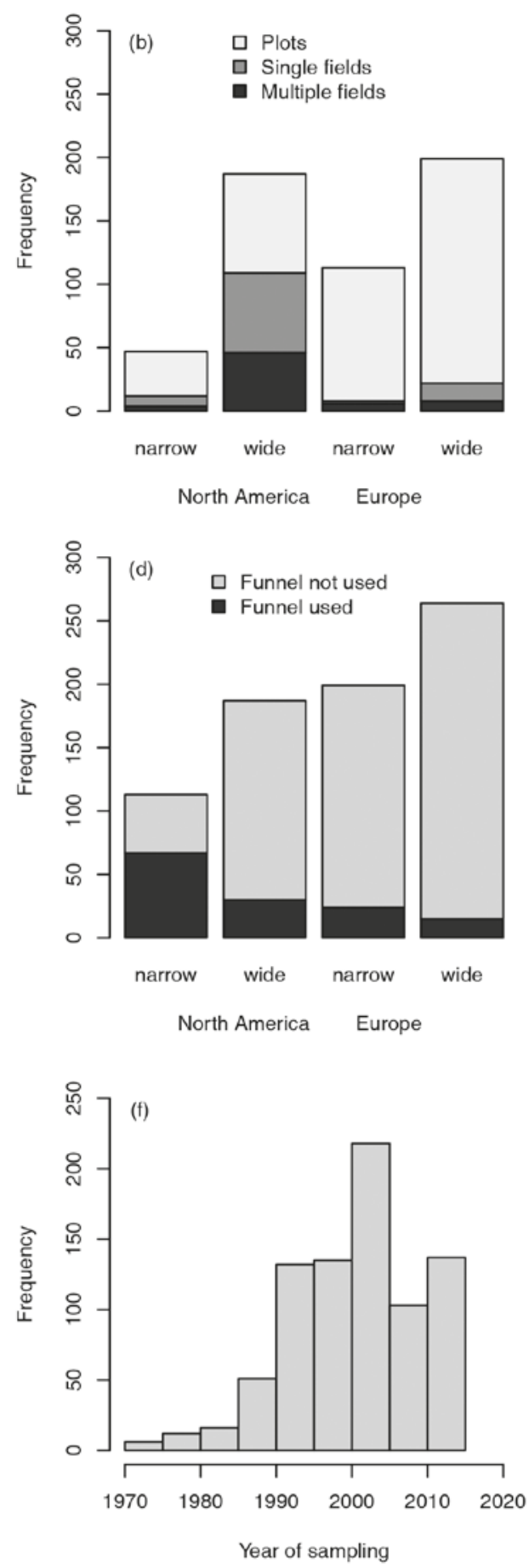

Fig. 1. Distribution of records in the data set with variables fundamental to the study design, sampling scheme and level of data aggregation in the source publications. (a) Number of data records according to aggregation over experimental units and sampling seasons. (b) Number of data records originating from North America and Europe, from crops with wide or narrow rows, and from plots, single fields, or multiple fields. (c) Number of data records related to experimental crops. C3 cereals include wheat $(n=141)$, barley (66), oats (3), triticale (2) and undefined cereals (10); C4 cereals include both sweet corn and corn for silage (260) and sorghum (2); legumes include pea (35), soybean (24), beans (18), lupin (6) and faba bean (4); root crops include potatoes (41), sugarbeet (31) and carrots (5); and vegetables consist of tomatoes (16), squash (10), melon (8), cauliflower (8), cabbage (7), zucchini (6) and onion (5). Cotton (6), oilseed rape (10) and sunflower (5) are single crop categories. (d) Number of data records based on trapping with or without funnels, and originating from North America or Europe, and from crops with wide or narrow rows. (e) Number of data records related to the collecting fluid used. Antifreeze include ethylene glycol (236), propylene glycol (171) and unspecified antifreeze (14), water includes water with (66) or without (41) diluted salt, alcohols include ethanol (17) and iso-propyl alcohol (8), other include $\mathrm{Na}_{3} \mathrm{PO}_{4}(4), \mathrm{CuSO}_{4}(12)$, natrium benzoate (2) and unspecified liquid (6), and acetic acid include mixtures that contain this ingredient (14). Formalin (144) and live traps without any collecting fluid (23) are single type categories; (f) Distribution of data records according to the year of sampling. 

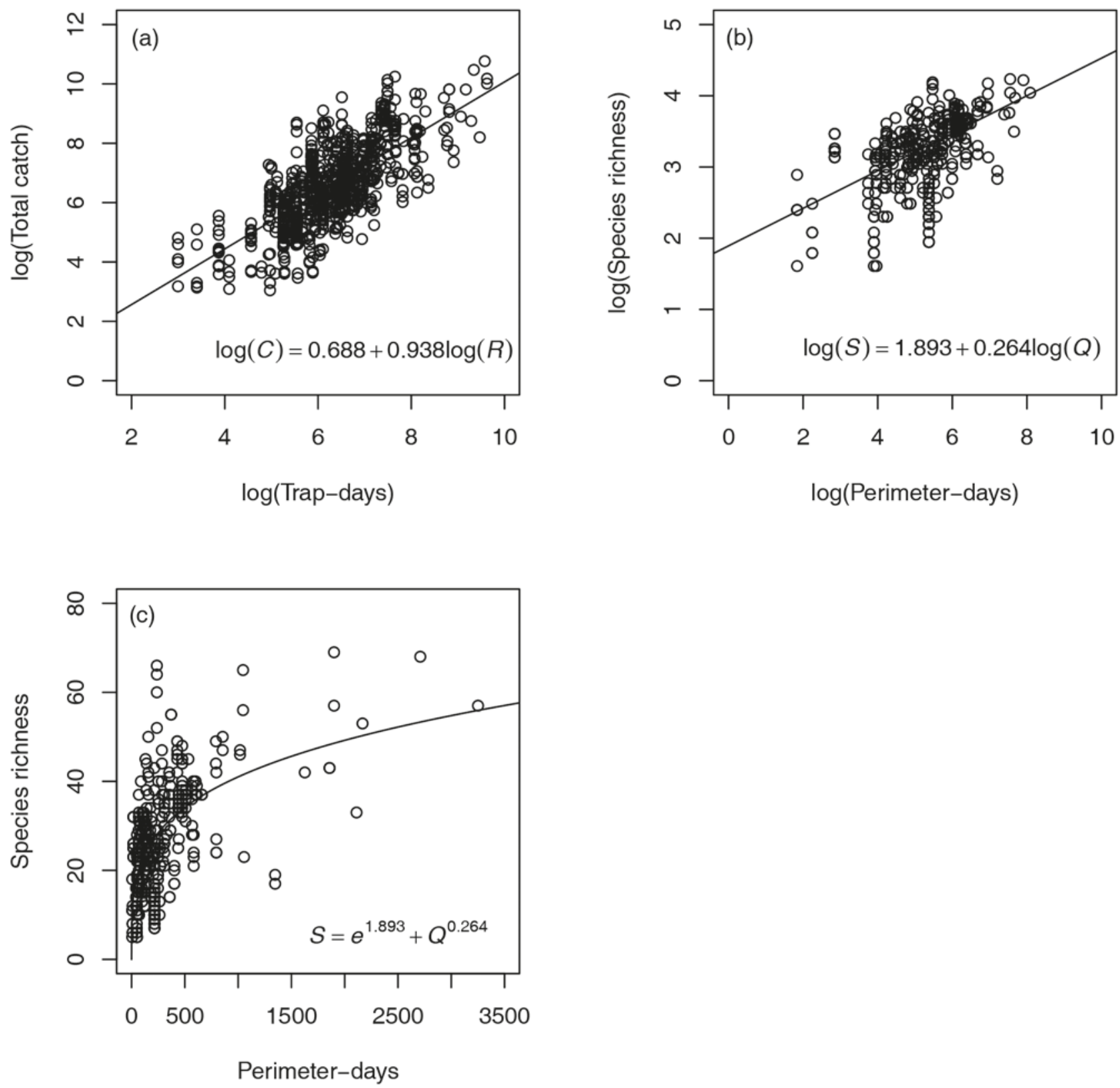

Fig. 2. Dependency of carabid pitfall catch on trapping effort. (a) The effect of trap-days (R) [log(trap days)] on the total catch [log(individuals)] (model C18 in Appendix S6); (b) The effect of perimeter-days (Q) [log(m days)] on the observed species richness $S$ [log(species)] (model S23 in Appendix S6); (c) same as (b) but on the natural scale.

\subsection{Factors influencing effort-adjusted catch size and species richness}

Models with single predictors indicated that effort-adjusted catch was significantly affected by Continent, Unit, RowWidth and Fluid, but not by Season and Funnel (Fig. 3). The $C P U E_{C}$ was on average $65 \%$ higher in Europe than in North America, and $32 \%$ lower in crops with wide rows than in crops with narrow rows. Records from multiple fields and plots had lower $C P U E_{C}$ by 39 and $53 \%$ than those from single fields. Live traps had $84 \%$ lower catch per unit effort, $C P U E_{C}$, than traps containing fluids based on acetic acid (which had the highest catch per unit effort), and 43 $\%$ less than traps with antifreeze-based fluids. The effortadjusted species richness was affected significantly by the RowWidth, Season and Funnel, but not by Continent, Unit and Fluid (Fig. 4). Effort-adjusted species richness, $C P U E_{S}$, was reduced by $29 \%$ in crops with wide rows compared to narrow rows, by $23 \%$ if data were aggregated over multiple seasons, but increased by $90 \%$ if funnels were used inside the traps. The analysis based on the comparison of the cumu- 
Continent

North America

Europe

Unit aggregation

multiple fields

single field

plots

Row width

narrow rows

wide rows

Season aggregation

single season

multiple seasons

Funnel

no funnel

funnel

Collecting fluid

acetic acid

alcohols

antifreeze

formalin

live

other

water

grand mean

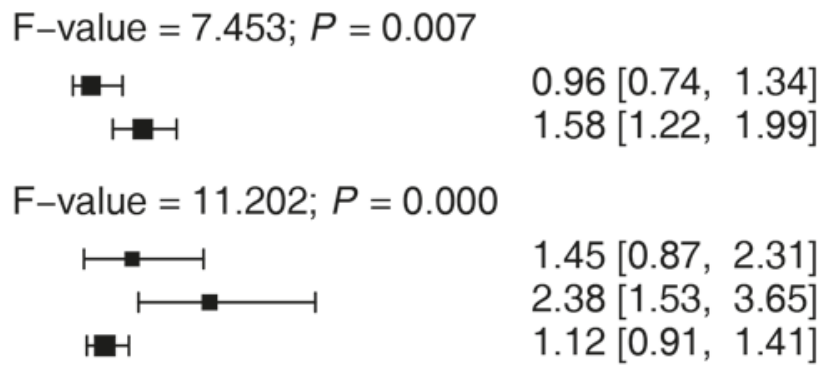

F-value $=16.827 ; P=0.000$

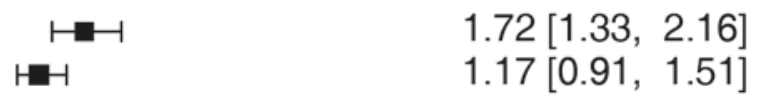

F-value $=0.205 ; P=0.651$

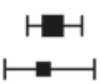

$1.35[1.05,1.70]$

$1.24[0.77,1.85]$

F-value $=0.004 ; P=0.947$

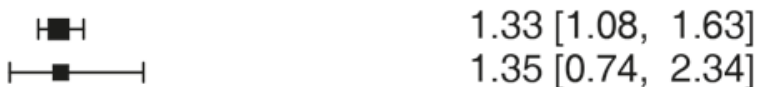

F-value $=3.109 ; P=0.008$

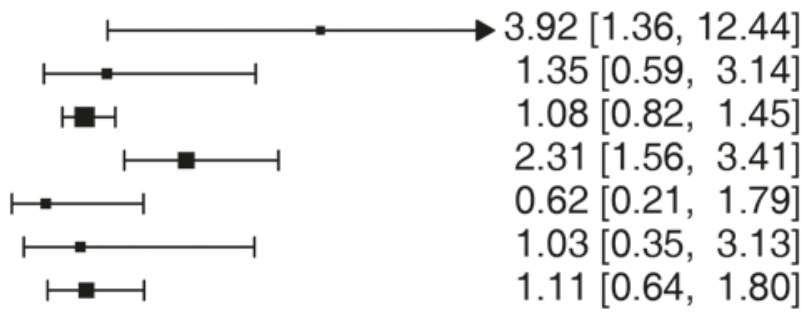

t-value $=3.164 ; P=0.002$

$1.33[1.08,1.61]$

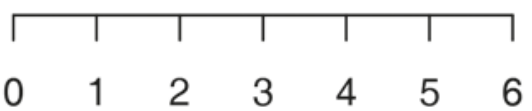

Estimated mean $C P U E_{C}$

Fig. 3. Estimated mean effort-adjusted catch, $C P U E_{C}$ [individuals (trap days)-1] , shown for variables potentially affecting the relationship with the pitfall catch and trapping effort. Size of the symbols are relative to sample size. Horizontal bars are $95 \% \mathrm{Cl}$ bootstrapped by the bootMer function (R package Ime4, 200 simulations).

lative probability distributions of $C P U E_{C}$ and $C P U E_{S}$ for the categorical variables provided results similar to the mixed models with single predictors (Appendix S7). Neither effortadjusted catch nor species richness showed a significant temporal trend over the period covered by this study (Fig. 5).

Multi-model inference lowered the level of significance of the factors influencing catch and number of species per unit effort. RowWidth was the only variable that significantly affected effort-adjusted catch in the averaged top models (Appendix S8), regardless of the information criterion used for model selection. The effect of other variables proposed by the single regression models (Fig. 3) cancelled each other out, probably due to correlations between inputs, but an important other explanation may be the reduced data set 


$\begin{array}{llr}\text { Continent } & \\ \text { North America } \\ \text { Europe }\end{array}$

Fig. 4. Estimated mean effort-adjusted species richness, $C P U E_{S}$ [species ( $m$ days)-0.25], shown for variables potentially affecting the relationship with the pitfall catch and trapping effort. Size of the symbols are relative to sample size. Horizontal bars are $95 \% \mathrm{Cl}$ bootstrapped by the bootMer function (R package Ime4, 200 simulations).

used for multi-model inference as only data records without missing data were included in this analysis. Using AICc, $C P U E_{C}$ was $30 \%$ lower in crops with wide rows than in crops with narrow rows (z-value $=3.788, P<0.001$ ), which is consistent with results of the single variable models. The values estimated based on BIC weights were similar to those calculated with AICc weights.
Effort-adjusted species richness was significantly affected by RowWidth, Funnel and Season if the model selection was based on AICc, and only by RowWidth if the model selection was based on BIC. Crops with wide rows reduced the $C P U E_{S}$ by $22 \%$ (AICc; z-value $=3.564, P<0.001$; BICbased selection gave very similar values), the use of a funnel increase the $C P U E_{S}$ by $66 \%$ (AICc; z-value $=2.603$, 

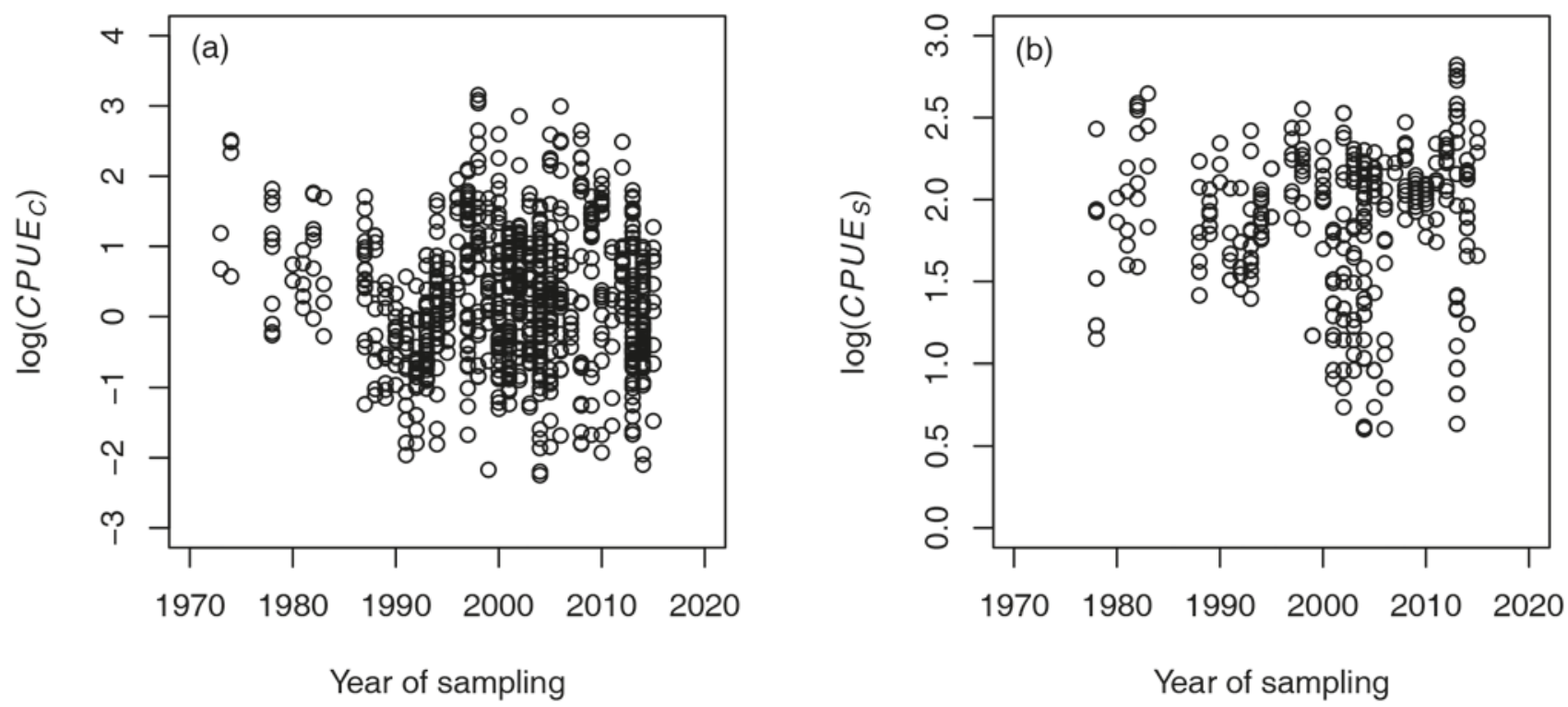

Fig. 5. Variation in the effort-adjusted catch, $C P U E_{C}$ [individuals (trap days)-1] (a), and effort-adjusted species richness, $C P U E_{S}$ [species ( $m$ days $)^{-0.25}$ (b) over the years of sampling covered by the data set.
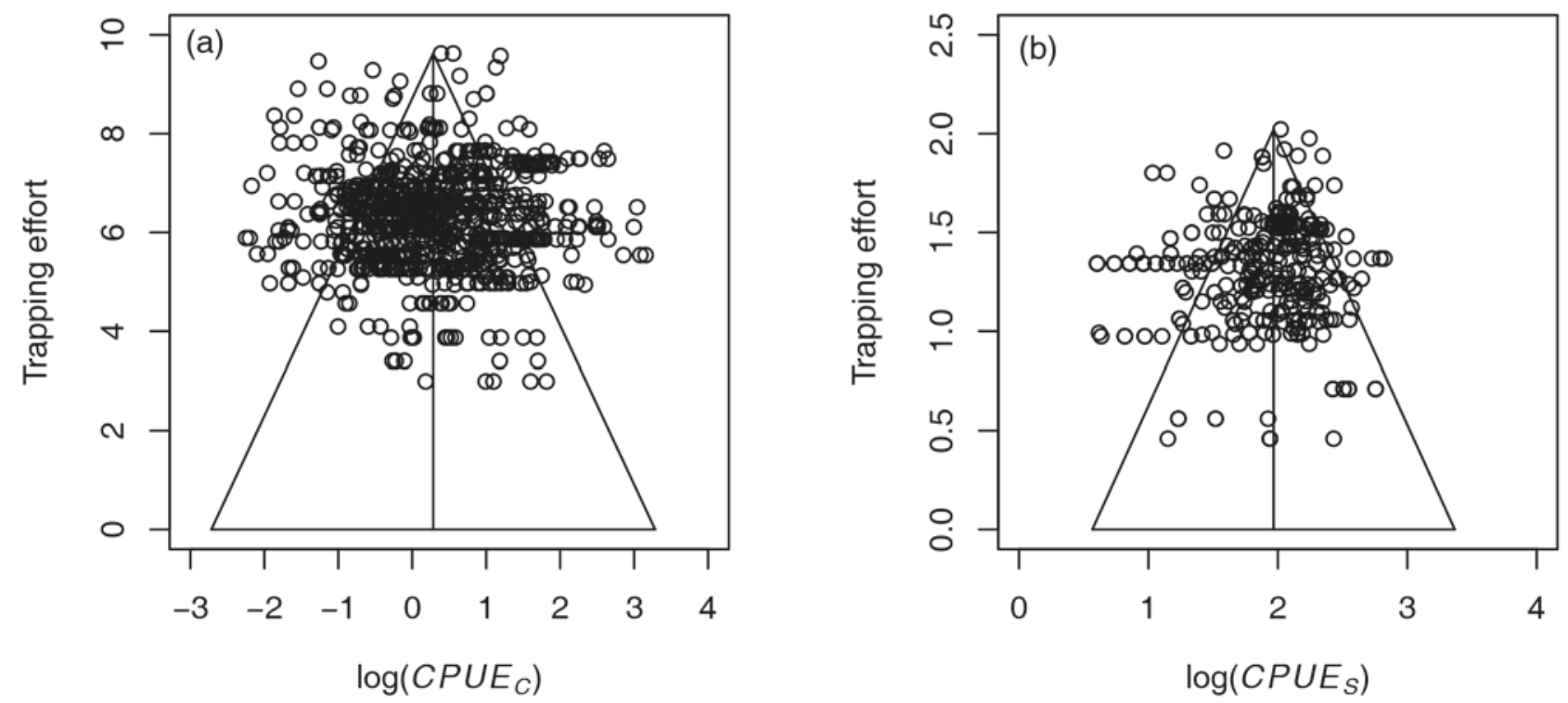

Fig. 6. Assessment of publication bias in the data included in the meta-analysis, using funnel plots of the effort-adjusted catch [log(individuals (trap days) $\left.{ }^{-1}\right)$ ] against trapping effort as trap-days [log(trap days)] (a), and the effort-adjusted species richness $\left[\log \left(\right.\right.$ species $\left.\left.(m \text { days })^{-0.25}\right)\right]$ against trapping effort as perimeter-days $\left[\log \left((m \text { days })^{0.25}\right)\right](\mathbf{b})$. The vertical lines represent the overall means on the log scale, as predicted by the null models. Log is the natural logarithm.

$P=0.009)$, and aggregation of data over multiple seasons reduced the $C P U E_{S}$ by $26 \%$ (AICc; $\mathrm{z}$-value $=2.075, P=$ 0.038). These values are also close to the results of single variable regression models (see above).

\subsection{Publication bias}

Studies with trapping effort of less than 20 trap days $(R=$ $\left.e^{3}\right)$, or ca. $1.7 \mathrm{~m} \mathrm{~d}\left(Q=e^{0.5}\right)$ were absent from the literature (Fig. 6). The variability in the $\log \left(C P U E_{C}\right)$ or $\log \left(C P U E_{S}\right)$ did not change with trapping effort (Fig. 6), which suggests 
that the variability is unrelated to the study precision and represents biological variation.

\section{Discussion}

This analysis showed that trap days was the most suitable measure for expressing trapping effort when analysing the number of carabid beetles caught in pitfall traps. The exponent of the allometric relationship was not significantly different from 1 , indicating that the catch is proportional to trapping effort, without significant curvature or saturation in the relationship. The best measure to express trapping effort when analysing species diversity of the catch was the number of meter days to the power of 0.25 , where the meters refer to total perimeter length of all traps while days refers to the time of trap exposure in the field. The exponent value of ca. 0.25 was significantly less than 1 , indicating that the relationship between trapping effort and species diversity is strongly non-linear, with species diversity increasing quite slowly with increases in effort, as measured by the number of traps, their perimeter, and the time of exposure. The finding of proportionality between the catch and effort in terms of trap-days validates the frequently-made presumption that the efficiency of trapping does not diminish with greater density of traps or longer time in the field. This conclusion is of course limited to the range of trap numbers and trapping durations commonly considered in this field of research and it is not implied that trapping efficiency could not be affected, e.g. when excessive numbers of traps are used. Also, the result is consistent over carabid communities that greatly differed in their composition.

We also found large heterogeneity across the records, demonstrating the importance of the local conditions for determination of the actual effort-corrected catch and richness, and this is largely captured by the random terms of the models. Large heterogeneity across the records would also suggest that to obtain more information about arthropod communities in arable land, it is of greater importance to sample more locations and more different conditions, than to expend additional trapping effort in any particular location or condition. The number of traps and fields in a sample should be determined by the question and the effect size researchers wish to detect, using power analyses (e.g. Perry et al. 2003; Bolker, 2008).

Although the single variable regression models identified multiple variables that were related to the effort-adjusted catch and species richness, model averaging indicated that the contrast between wide and narrow row crops was the major factor while other variables did not have an identifiable contribution to the catch or diversity in an overarching multi-variable analysis. This discrepancy between the two approaches may be due to the fact that the influence of particular factors, though locally important, were confounded and thus cancel each other out in a global analysis. Lower power of the model averaging may also contribute to less significant results as this analysis was based only on ca. 90 $\%$ of the records. Single variable analyses can use all the data that have the results for the studied independent variable whereas the model averaging requires information on all the independent variables. Based on both analyses, we conclude that no concern is needed in a future (meta-) analysis about the variability in experimental design, presentation, trap design or other factors varying across source studies when conducting meta-analyses on carabid activity-density and diversity. Nevertheless, standardization of the pitfall catch for effort is still needed to make comparison across studies possible.

Crops with wide or narrow rows differ in structure and phenology. Crops with wider rows (e.g. corn) constitute a less favourable environment, because there is greater proportion of bare soil that needs longer time to reach a closed canopy. Bare soil is unfavourable for many carabid species since exposure increases the risk of predation (Eyre et al. 2013; Seidl et al. 2020), and diurnal changes in microclimate are more prominent in wide row crops than under a more closed crop canopy (Rosenberg et al. 1983; Krédl et al. 2013). Crops with wider rows also allow crop management, such as mechanical weed control, which may be more intensive and extend longer over the season, potentially disturbing development stages of carabids present in soil.

The effort-adjusted species richness was affected by the level of data aggregation over trapping years (i.e. single year vs. multiple years) and the use of funnels inside the traps. The former can readily be explained by the fact that even though the local populations of carabids species show asynchronous fluctuations between seasons (Kotze et al. 2011), which results in a change in the relative contribution of particular species to the catch between years (e.g. Veselý \& Sarapatka 2008), the number of newly recorded species per year on sites sampled for multiple seasons is low. Increasing the trapping effort over more seasons on the same site brings disproportionately fewer new species recorded than adding a new site, sampled with the same effort. The presence of funnels increased observed species richness, which may be associated with a reduction in the probability of escaping from the traps (Obrist \& Duelli 1996). Interestingly, the use of funnels did not affect the number of individuals caught.

We were unable to detect trends in $C P U E_{C}$ or $C P U E_{S}$ over the 43 years covered by the data set, suggesting that carabid populations have not declined in abundance or diversity in arable fields on a broader geographical scale over this period. This result was remarkable and in contrast to the monitoring programmes on local (Pozsgai et al. 2016; van Noordwijk et al. 2017) or national scales (Brooks et al. 2012; Ewald et al. 2015), which have found carabid populations to have declined over time, as well as with general perception that insect populations decline in terrestrial ecosystems (Eggleton 2020; van Klink et al. 2020). Since the present data set originates from many local independent 
studies performed in different years, it may be less sensitive to site-specific inter-annual fluctuations (Kotze et al. 2011). A biological explanation for the lack of any trend might be that species inhabiting annual arable fields are adapted to early successional stages of vegetation development that arable fields are in fact representing, and to periodical disturbances due to management measures within the fields. Given that local declines of carabids, as well as other insects, have been observed in non-crop semi-natural habitats (Brooks et al. 2012; Poszgai et al. 2016; Hallmann et al. 2017) a reasonable expectation would be that this decline should spill over into arable fields as many carabid species recolonize fields from these non-crop habitats (Tscharntke et al. 2005). The present data, however, do not provide support for this assumption. Evaluating whether the community composition of the study group had changed in arable fields over the years was not, however, possible for our data because this evaluation would require different data extraction procedures than we have employed.

Pitfall catches cannot be directly interpreted as abundance estimates because the number of trapped individuals depends not only on their population density but also on their activity (particularly movement speed) and behaviour (Heydemann 1957; Adis 1979; Mols 1993; Wallin \& Ekbom 1994; Saska et al. 2013; Engel et al. 2017). Our results do beg the question: "Can the newly established relationships for CPUE help us to relate the size of the pitfall catch to the real densities or diversity of carabid population in the field?" Not on its own, but since we resolved one of variables from the relationship between the catch size and density, $C=q E N$, (Harley et al. 2001; Martell 2008), i.e. trapping effort $(E)$, we have advanced closer to a reliable approximation of the field densities and diversity from the pitfall trap catches. What remains to be investigated is the quantification of trappability coefficients $q$ for a range of species, because the likelihood of being trapped is likely to be species specific and size dependent (Halsall \& Wratten 1988; Engel et al. 2017). Thus, eq. 1 can be further extended to consider species specific trappability coefficient $q_{i}$. A relationship for $C P U E_{C}$, with species-specific catches $C_{i}$ and trapping effort expressed as trap-days $R$ would be:

$\log \left(\frac{\sum C_{i}}{R}\right)=\log \left(\sum q_{i} N_{i}\right)$

Trappability coefficients $q_{i}$ can be obtained by trapping beetles in enclosures with natural or manipulated densities, in various environments and in different abiotic conditions.

In this paper we establish relationships for the catch of carabid beetles, expressed as the number of individuals and the number of species, as a function of the pitfall trapping effort.

This method could be very useful for revealing the effects on carabid communities of other variables of inter- est related to agricultural management, such as pesticide and herbicide use, tillage, fertilization, crop seasonality and crop rotations that potentially affect carabid diversity and ecosystem functions. These will be investigated in a follow-up study.

This method applied here to carabid beetles could similarly be applied to other taxa with similar ecology, trapped using pitfalls, including ectothermic vertebrates or small mammals, or for other trapping devices that give activitydensity estimates, such as window or suction traps used for collecting flying insects. Standardization of the pitfall catch for trapping effort will be very useful in future systematic comparisons of multiple independent catches, since the data collected in various conditions are thus made more comparable. This approach removes one of the obstacles that has hampered meta-analyses of pitfall trap data.

Authors' contribution: PS, WvdW and DB conceived the study; PS, DM and WvdW conceptualized the analysis; PS performed the literature search, extracted the data, performed the analysis, created tables and figures, and led writing of the manuscript; DM, DB and WvdW contributed to writing and edited the final version; all authors have read and approved the final version of this paper.

Data availability: Data is available with the first author upon reasonable request.

Acknowledgements: This work was conducted within an ERANET C-IPM project BioAWARE. The stay of P.S. at Wageningen University was funded by the Mobility EU-Funds project CZ.02.2. 69/0.0/0.0/16_027/0008503, awarded to the Crop Research Institute. Finishing of the work was supported by the institutional support from the Ministry of Agriculture of the Czech Republic - MZE-RO0418.

\section{References}

Adis, J. (1979). Problems of interpreting arthropod sampling with pitfall traps. Zoologischer Anzeiger, 202, 177-184.

Barton, K. (2009). MuMIn: Multi-model inference. R package. http://R-Forge.R-project.org/projects/mumin/

Bates, D., Machler, M., Bolker, B. M., \& Walker, S. C. (2015). Fitting Linear Mixed-Effects Models Using lme4. Journal of Statistical Software, 67(1), 1-48. https://doi.org/10.18637/jss. v067.i01

Bohan, D. A., Boursault, A., Brooks, D. R., \& Petit, S. (2011). National-scale regulation of the weed seedbank by carabid predators. Journal of Applied Ecology, 48(4), 888-898. https://doi. org/10.1111/j.1365-2664.2011.02008.x

Bolker, B. M. (2008). Ecological Models and Data in R. Princeton University Press.

Bovendorp, R. S., Mccleery, R. A., \& Galetti, M. (2017). Optimising sampling methods for small mammal communities in Neotropical rainforests. Mammal Review, 47(2), 148-158. https://doi.org/10.1111/mam.12088 
Brooks, D. R., Bater, J. E., Clark, S. J., Monteith, D. T., Andrews, C., Corbett, S. J., ... Chapman, J. W. (2012). Large carabid beetle declines in a United Kingdom monitoring network increases evidence for a widespread loss in insect biodiversity. Journal of Applied Ecology, 49(5), 1009-1019. https://doi.org/10.1111/ j.1365-2664.2012.02194.x

Burnham, K. P., \& Anderson, D. R. (2002). Model Selection and Multimodel Inference: A Practical Information-Theoretic Approach. New York: Springer-Verlag.

Eggleton, P. (2020). The State of the World's Insects. Annual Review of Environment and Resources, 45(1), 61-82. https:// doi.org/10.1146/annurev-environ-012420-050035

Engel, J., Hertzog, L., Tiede, J., Wagg, C., Ebeling, A., Briesen, H., \& Weisser, W. W. (2017). Pitfall trap sampling bias depends on body mass, temperature, and trap number: Insights from an individual-based model. Ecosphere, 8(4), e01790. https://doi.org/ $10.1002 /$ ecs 2.1790

Ewald, J. A., Wheatley, C. J., Aebischer, N. J., Moreby, S. J., Duffield, S. J., Crick, H. Q. P., \& Morecroft, M. B. (2015). Influences of extreme weather, climate and pesticide use on invertebrates in cereal fields over 42 years. Global Change Biology, 21(11), 3931-3950. https://doi.org/10.1111/gcb.13026

Eyre, M. D., Luff, M. L., \& Leifert, C. (2013). Crop, field boundary, productivity and disturbance influences on ground beetles (Coleoptera, Carabidae) in the agroecosystem. Agriculture, Ecosystems \& Environment, 165, 60-67. https://doi.org/ 10.1016/j.agee.2012.12.009

Frei, B., Guenay, Y., Bohan, D. A., Traugott, M., \& Wallinger, C. (2019). Molecular analysis indicates high levels of carabid weed seed consumption in cereal fields across Central Europe. Journal of Pest Science, 92(3), 935-942. https://doi.org/10.1007/s10340019-01109-5

Gotelli, N. J., \& Colwell, R. K. (2001). Quantifying biodiversity: procedures and pitfalls in the measurement and comparison of species richness. Ecology Letters 4, 379-391.

Grueber, C. E., Nakagawa, S., Laws, R. J., \& Jamieson, I. G. (2011). Multimodel inference in ecology and evolution: Challenges and solutions. Journal of Evolutionary Biology, 24(4), 699-711. https://doi.org/10.1111/j.1420-9101.2010.02210.x

Hallmann, C. A., Sorg, M., Jongejans, E., Siepel, H., Hofland, N., Schwan, H., ... de Kroon, H. (2017). More than 75 percent decline over 27 years in total flying insect biomass in protected areas. PLoS One, 12(10), e0185809. https://doi.org/10.1371/ journal.pone.0185809

Halsall, N. B., \& Wratten, S. D. (1988). The efficiency of pitfall trapping for polyphagous predatory Carabidae. Ecological Entomology, 13(3), 293-299. https://doi.org/10.1111/j.13652311.1988.tb00359.x

Harley, S. J., Myers, R. A., \& Dunn, A. (2001). Is catch-per-uniteffort proportional to abundance? Canadian Journal of Fisheries and Aquatic Sciences, 58(9), 1760-1772. https://doi.org/ 10.1139/f01-112

Heydemann, B. (1957). Die Biotopstructur als Raumwiderstand und Raumfülle für die Tierwelt. Verhandlungen der Deutschen Zoologischen Gesellschaft Hamburg, 332-347.

Hohbein, R. R., \& Conway, C. J. (2018). Pitfall traps: A review of methods for estimating arthropod abundance. Wildlife Society Bulletin, 42(4), 597-606. https://doi.org/10.1002/wsb.928

Jung, J.-K., Jeong, J.-C., \& Lee, J.-H. (2019). Effects of pitfall trap size and sampling duration on collection of ground beetles
(Coleoptera: Carabidae) in temperate forests. Entomological Research, 49(5), 229-236. https://doi.org/10.1111/1748-5967. 12358

Koivula, M., Kotze, D. J., Hiisivuori, L., \& Rita, H. (2003). Pitfall trap efficiency: Do trap size, collecting fluid and vegetation structure matter? Entomologica Fennica, 14(1), 1-14. https:// doi.org/10.33338/ef.84167

Kotze, D. J., Brandmayr, P., Casale, A., Dauffy-Richard, E., Dekoninck, W., Koivula, M. J., ... Zetto, T. (2011). Forty years of carabid beetle research in Europe - from taxonomy, biology, ecology and population studies to bioindication, habitat assessment and conservation. ZooKeys, 100, 55-148. https://doi. org/10.3897/zookeys.100.1523

Kotze, D. J., O’Hara, R. B., \& Lehvävirta, S. (2012). Dealing with varying detection probability, unequal sample sizes and clumped distributions in count data. PLoS One, 7(7), e40923. https://doi. org/10.1371/journal.pone.0040923

Krédl, Z., Středa, T., Pokorny, R., Kmoch, M., \& Brotan, J. (2013). Microclimate in the vertical profile of wheat, rape and maize canopies. Acta Universitatis Agriculturae et Silviculturae Mendelianae Brunensis, 60(1), 79-90. https://doi.org/10.11118/ actaun201260010079

Kromp, B. (1989). Carabid beetle communities (Carabidae, Coleoptera) in biologically and conventionally farmed agroecosystems. Agriculture, Ecosystems \& Environment, 27(1-4), 241-251. https://doi.org/10.1016/0167-8809(89)90089-3

Luff, M. L. (1975). Some features influencing the efficiency of pitfall traps. Oecologia, 19(4), 345-357. https://doi.org/10.1007/ BF00348110

Makowski, D., Piraux, F., \& Brun, F. (2019). From Experimental Network to Meta-analysis. Mehods and Applications with $R$ for Agronomic ad Environmental Sciences. Dordrecht: Springer.

Martell, S. J. D. (2008). Fisheries Management. In S. E. Jørgensen \& B. D. Fath (Eds.), Encyclopedia of Ecology (pp. 1572-1582). Oxford: Academic Press. https://doi.org/10.1016/B978-0080 45405-4.00206-8

Mols, P. J. M. (1993). Walking to survive. Searching, feeding and egg production of the carabid beetles Pterostichus coerulescens L. (= Poecilus versicolor Sturm). Ph.D. Thesis, Agricultural University Wageningen.

Nakagawa, S., \& Schielzeth, H. (2013). A general and simple method for obtaining R2 from generalized linear mixed-effects models. Methods in Ecology and Evolution, 4(2), 133-142. https://doi.org/10.1111/j.2041-210x.2012.00261.x

Obrist, M., \& Duelli, P. (1996). Trapping efficiency of funnel and cup-traps for epigeal arthropods. Mitteilungen der Schweizerische Entomologische Gesellschaft, 69, 361-369.

Pekár, S. (2002). Differential effects of formaldehyde concentration and detergent on the catching efficiency of surface active arthropods by pitfall traps. Pedobiologia, 46(6), 539-547. https://doi. org/10.1078/0031-4056-00158

Perry, J. N., Rothery, P., Clark, S. J., Heard, M. S., \& Hawes, C. (2003). Design, analysis and statistical power of the Farm-Scale Evaluations of genetically modified herbicide-tolerant crops. Journal of Applied Ecology, 40(1), 17-31. https://doi.org/ 10.1046/j.1365-2664.2003.00786.x

Pozsgai, G., Baird, J., Littlewood, N. A., Pakeman, R. J., \& Young, M. R. (2016). Long-term changes in ground beetle (Coleoptera: Carabidae) assemblages in Scotland. Ecological Entomology, 41(2), 157-167. https://doi.org/10.1111/een.12288 
R Core Team (2019). R: A Language and Environment for Statistical Computing. R Foundation for Statistical Computing, Vienna, Austria. Available at http://www.R-project.org

Rosenberg, N. J., Blad, B. L., \& Verma, S. B. (1983). Microclimate: The Biological Environment. Wiley.

Saska, P., van der Werf, W., Hemerik, L., Luff, M. L., Hatten, T. D., \& Honek, A. (2013). Temperature effects on pitfall catches of epigeal arthropods: A model and method for bias correction. Journal of Applied Ecology, 50(1), 181-189. https://doi. org/10.1111/1365-2664.12023

Seidl, M., Gonzalez, E., Kadlec, T., Saska, P., \& Knapp, M. (2020). Temporary non-crop habitats within arable fields: The effects of field defects on carabid beetle assemblages. Agriculture, Ecosystems \& Environment, 293, 106856. https://doi.org/ 10.1016/j.agee.2020.106856

Spence-Bailey, L. M., Nimmo, D. G., Kelly, L. T., Bennett, A. F., \& Clarke, M. F. (2010). Maximising trapping efficiency in reptile surveys: The role of seasonality, weather conditions and moon phase on capture success. Wildlife Research, 37(2), 104-115. https://doi.org/10.1071/WR09157

Sunderland, K. D. (2002). Invertebrate pest control by carabids. In J. M. Holland (Ed.), The Agroecology of Carabid Beetles (pp. 165-214). Andover: Intercept.

Tscharntke, T., Rand, T. A., \& Bianchi, F. J. J. A. (2005). The landscape context of trophic interactions: Insect spillover across the crop-noncrop interface. Annales Zoologici Fennici, 42, 421-432.

Turin, H., Alders, K., den Boer, P. J., van Essen, S., Heijerman, T., Laane, W., \& Penterman, E. (1991). Ecological characterization of carabid species (Coleoptera, Carabidae) in the Netherlands from thirty years of pitfall sampling. Tijdschrift voor Entomologie, 134, 279-304. van Klink, R., Bowler, D. E., Gongalsky, K. B., Swengel, A. B., Gentile, A., \& Chase, J. M. (2020). Meta-analysis reveals declines in terrestrial but increases in freshwater insect abundances. Science, 368(6489), 417-420. https://doi.org/10.1126/ science.aax 9931

van Noordwijk, C. G. E., Baeten, L., Turin, H., Heijerman, T., Alders, K., Boer, P., ... Bonte, D. (2017). 17 years of grassland management leads to parallel local and regional biodiversity shifts among a wide range of taxonomic groups. Biodiversity and Conservation, 26(3), 717-734. https://doi.org/10.1007/ s10531-016-1269-5

Veselý, M., \& Sarapatka, B. (2008). Effects of conversion to organic farming on carabid beetles (Carabidae) in experimental fields in the Czech Republic. Biological Agriculture and Horticulture, 25(4), 289-309. https://doi.org/10.1080/01448765.2008.9755057

Wallin, H., \& Ekbom, B. (1994). Influence of hunger level and prey densities on movement patterns in three species of Pterostichus beetles (Coleoptera: Carabidae). Environmental Entomology, 23(5), 1171-1181. https://doi.org/10.1093/ee/23.5.1171

The pdf version (Adobe JavaScript must be enabled) of this paper includes an electronic supplement: Supplement S1-S8

Manuscript received: 6 October 2020

Revisions requested: 9 November 2020

Modified version received: 16 November 2020

Accepted: 15 December 2020 